\title{
Myeloperoxidase-mediated Protein Lysine Oxidation Generates 2- aminoadipic acid and Lysine nitrile in vivo
}

Hongqiao Lin

Cleveland Clinic

Bruce S. Levison

Cleveland Clinic

Jennifer A. Buffa

Cleveland Clinic

Ying Huang

Cleveland Clinic

Xiaoming Fu

Cleveland Clinic

Follow this and additional works at: https://engagedscholarship.csuohio.edu/scichem_facpub

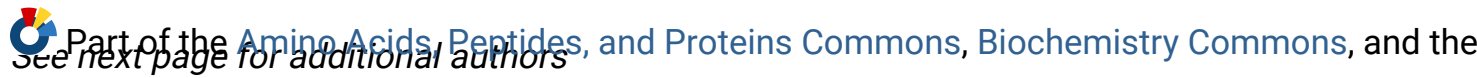
Chemistry Commons

How does access to this work benefit you? Let us know!

\section{Publisher's Statement}

Link to publisher version: http://dx.doi.org/10.1016/j.freeradbiomed.2017.01.006

\section{Recommended Citation}

Lin, Hongqiao; Levison, Bruce S.; Buffa, Jennifer A.; Huang, Ying; Fu, Xiaoming; Wang, Zeneng; Gogonea, Valentin; DiDonato, Joseph A.; and Hazen, Stanley L., "Myeloperoxidase-mediated Protein Lysine Oxidation Generates 2- aminoadipic acid and Lysine nitrile in vivo" (2017). Chemistry Faculty Publications. 527. https://engagedscholarship.csuohio.edu/scichem_facpub/527 


\section{Authors}

Hongqiao Lin, Bruce S. Levison, Jennifer A. Buffa, Ying Huang, Xiaoming Fu, Zeneng Wang, Valentin Gogonea, Joseph A. DiDonato, and Stanley L. Hazen 
Original article

\title{
Myeloperoxidase-mediated protein lysine oxidation generates 2- aminoadipic acid and lysine nitrile in vivo
}

\author{
Hongqiao Lin, Bruce S. Levison, Jennifer A. Buffa, Ying Huang, Xiaoming Fu, Zeneng \\ Wang, Valentin Gogonea, Joseph A. DiDonato, Stanley L. Hazen
}

\section{A R T I C L E I N F O}

Keywords:

Lysine

2-aminoadipic acid

Lysine nitrile

Neutrophil

Myeloperoxidase

Hypochlorous acid

Atherosclerosis

Diabetes

Inflammation

Chloramine

\begin{abstract}
A B S T R A C T
Recent studies reveal 2-aminoadipic acid (2-AAA) is both elevated in subjects at risk for diabetes and mechanistically linked to glucose homeostasis. Prior studies also suggest enrichment of protein-bound 2-AAA as an oxidative post-translational modification of lysyl residues in tissues associated with degenerative diseases of aging. While in vitro studies suggest redox active transition metals or myeloperoxidase (MPO) generated hypochlorous acid $(\mathrm{HOCl})$ may produce protein-bound 2-AAA, the mechanism(s) responsible for generation of 2AAA during inflammatory diseases are unknown. In initial studies we observed that traditional acid- or basecatalyzed protein hydrolysis methods previously employed to measure tissue 2-AAA can artificially generate protein-bound 2-AAA from an alternative potential lysine oxidative product, lysine nitrile (LysCN). Using a validated protease-based digestion method coupled with stable isotope dilution LC/MS/MS, we now report protein bound 2-AAA and LysCN are both formed by hypochlorous acid ( $\mathrm{HOCl}$ ) and the $\mathrm{MPO} / \mathrm{H}_{2} \mathrm{O}_{2} / \mathrm{Cl}^{-}$system of leukocytes. At low molar ratio of oxidant to target protein $\mathrm{N}^{\varepsilon}$-lysine moiety, 2-AAA is formed via an initial $\mathrm{N}^{\varepsilon}$ monochloramine intermediate, which ultimately produces the more stable 2-AAA end-product via sequential generation of transient imine and semialdehyde intermediates. At higher oxidant to target protein $\mathrm{N}^{\varepsilon}$-lysine amine ratios, protein-bound LysCN is formed via initial generation of a lysine $\mathrm{N}^{\varepsilon}$-dichloramine intermediate. In studies employing MPO knockout mice and an acute inflammation model, we show that both free and proteinbound 2-AAA, and in lower yield, protein-bound LysCN, are formed by MPO in vivo during inflammation. Finally, both 2-AAA and to lesser extent LysCN are shown to be enriched in human aortic atherosclerotic plaque, a tissue known to harbor multiple MPO-catalyzed protein oxidation products. Collectively, these results show that MPO-mediated oxidation of protein lysyl residues serves as a mechanism for producing 2-AAA and LysCN in vivo. These studies further support involvement of MPO-catalyzed oxidative processes in both the development of atherosclerosis and diabetes risk.
\end{abstract}

\section{Introduction}

2-Aminoadipic acid (2-AAA) is a low abundance amino acid previously suggested as an intermediate in some minor pathways of lysine catabolism in humans $[1,2]$. Interest in this relatively uncommon amino acid has increased recently, however, due to its suggested enrichment both in disease-associated tissues and plasma in subjects at risk for development of diabetes. For example, using an untargeted metabolomics approach, Gerszten and colleagues recently reported that plasma levels of 2-AAA herald increased future risk of developing diabetes [3]. Moreover, physiological levels of 2-AAA were shown to promote pancreatic beta cell insulin secretion and lower plasma glucose levels in murine models, further suggesting potential involvement of 2AAA as a modulator of glucose homeostasis [3]. In earlier studies it was suggested that protein lysyl residue oxidation by myeloperoxidase (MPO) - generated halogenating oxidants [4-10] may serve as a possible mechanism for generation of 2-AAA as a post translational modification of protein and lipoprotein lysyl residues [11]. Subsequent

Abbreviations: $m / z$, mass to charge; MPO, myeloperoxidase; 2-AAA, 2-aminoadipic acid; LysCN, lysine nitrile; Ac-Lys, $\mathrm{N}^{\alpha}$-acetyl-lysine; Ac-2AAA, $\mathrm{N}^{\alpha}$-acetyl-2-aminoadipic acid; AcLysCN, ${ }^{\alpha}$-acetyl-lysine nitrile; PMN, polymorphonuclear leukocytes; PMA, Phorbol 12-myristate 13-acetate; TG, thioglycollate; ZM, zymosan 
studies by both our group and Monnier and colleagues suggested not only MPO, but also metal catalyzed oxidative processes may participate in 2-AAA formation [11-14]. Indeed, protein bound 2-AAA has been reported to be enriched at sites known to harbor enhanced levels of protein oxidation products, including high density lipoprotein recovered from human atherosclerotic lesions, and insoluble collagen from aged skin, particularly from subjects with diabetes or renal disease [1114]. Interestingly, while biosynthetic pathways for generating 2-AAA are not observed in mammals, 2-AAA is a reported intermediate in the synthesis of lysine in certain fungi, as well as in the biosynthesis of penicillin in $\beta$-lactam-producing fungi $[15,16]$. It has also been reported as a metabolite produced from bacteria of the genus Thermus [17]. Despite the association between 2-AAA levels and the risk for developing diabetes [3], and its potential links to both vascular disease and degenerative diseases of aging [11-14], neither direct demonstration of oxidative pathway(s) that may participate in 2-AAA formation in vivo in mammals, nor detailed investigation of the biochemical pathway and structural intermediates involved in 2-AAA formation from protein lysyl residues, have been reported.

Wilson and colleagues recently reported that the major product of protein lysyl residue oxidation by reagent hypochlorous acid ( $\mathrm{HOCl})$ is not 2-AAA, but instead the unusual adduct lysine nitrile (LysCN, 2amino-5-cyanopentanoic acid) [18]. While these purely in vitro studies used a high $\mathrm{HOCl}$ relative to target (protein lysyl residue) ratio, they reported up to $80 \%$ yield of LysCN when a maximal $\mathrm{HOCl}$ to target ratio is used ( $\sim 100$ to 600 -fold excess) [18]. Nitriles in general can be acid labile [19], and acid hydrolysis was used in all (including our own) prior reported studies detecting protein-bound 2-AAA enrichment in tissues [11-14]. These provocative results suggesting LysCN as a potential $\mathrm{HOCl}$ generated oxidation product of protein lysyl residues therefore raised concerns to us of whether protein-bound 2-AAA is even a post translational oxidation product that exists in vivo, and whether 2-AAA is formed by the MPO/ $\mathrm{H}_{2} \mathrm{O}_{2} / \mathrm{Cl}^{-}$system in vivo.

In this paper we report on our pursuit to elucidate the products and reaction mechanisms of protein lysyl residue oxidation by $\mathrm{HOCl}[6,20-$ 25], MPO-generated chlorinating oxidants [4,5,7-10], and activated leukocytes both in vitro and in animal models employing wild type (WT) and MPO knockout (MPO-KO) mice. The studies presented herein establish that 2-AAA is a major, and LysCN a minor, post translational oxidation product of lysyl residues formed at sites of inflammation. Our studies further demonstrate substantial enrichment of both 2-AAA and LysCN within human aortic atherosclerotic plaque, a site previously shown to harbor enriched content of both MPO and alternative MPOgenerated oxidation products $[5,10,26-29]$, and elucidate the reaction pathway responsible for MPO-generated chlorinating oxidants in forming these lysine oxidation products.

\section{Materials and methods}

\subsection{Materials}

$\mathrm{N}^{\alpha}$-Boc-L-Lysine and $\mathrm{N}^{\alpha}$-acetyl-L-Lysine used as surrogates for protein lysyl residues were purchased from Chem-Impex International, Inc. (Wood Dale, Illinois). $\mathrm{D}_{3}$-2-aminoadipic acid was purchased from $\mathrm{C} / \mathrm{D} / \mathrm{N}$ isotopes Inc. (Pointe-Claire, Quebec). ${ }^{13} \mathrm{C}_{6}$, ${ }^{15} \mathrm{~N}_{2}$-Lysine was purchased from Cambridge isotope laboratories, Inc. (Andover, Massachusetts). Sodium hypochlorite ( $\mathrm{NaOCl}$ ), $\mathrm{H}_{2} \mathrm{O}_{2}$, ammonium hydroxide $\left(\mathrm{NH}_{4} \mathrm{OH}\right)$, trifluoroacetic acid and organic solvents were obtained from Fisher Scientific Co. Pronase was purchased from Roche life science (Indianapolis, Indiana). SAX SPE cartridges were obtained from Jordi lab (Mansfield, Massachusetts). Axis-Shield Polymorphprep was purchased from Cosmo Bio USA (Carlsbad, California). All other materials were obtained from Sigma-Aldrich, unless otherwise indicated.

\subsection{Ethical considerations}

All animal model studies were approved by the Institutional Animal Care and Use Committee of the Cleveland Clinic. All study protocols and informed consent for human subjects were approved by the Cleveland Clinic Institutional Review Board. Informed consents were obtained for isolation of human MPO, neutrophils and all other subject samples.

\subsection{General procedures}

In vitro oxidation reactions were performed in $50 \mathrm{mM}$ phosphate buffer (PB), $\mathrm{pH}=7.0$ supplemented with $100 \mu \mathrm{M}$ diethylene triamine pentaacetic acid (DTPA). The concentrations of $\mathrm{NaOCl}$ and $\mathrm{H}_{2} \mathrm{O}_{2}$ were determined spectrophotometrically $\left(\varepsilon 292(\mathrm{NaOCl})=350 \mathrm{M}^{-1} \mathrm{~cm}^{-1}\right.$ [30] and $\left(\varepsilon 240\left(\mathrm{H}_{2} \mathrm{O}_{2}\right)=39.4 \mathrm{M}^{-1} \mathrm{~cm}^{-1}\right.$ [31]). Human MPO was isolated, characterized and quantified as described [7]. Human neutrophils were isolated by ficoll-hypaque buoyant density centrifugation as described previously [32]. Phorbol myristate acetate was prepared in dimethyl sulfoxide (DMSO). Cell experiments were performed in Hanks' balanced salt solution, $\mathrm{pH} 7.2$ (no calcium, magnesium, or phenol red) (Thermo Fisher) with $100 \mu \mathrm{M}$ DTPA.

\subsection{Clinical specimens}

Human aortic tissues were recovered at the time of vascular or heart transplantation surgery. All tissues were rinsed in ice-cold normal saline immediately, submerged in buffer ( $65 \mathrm{mM}$ sodium phosphate, $\mathrm{pH} 7.4$, $100 \mu \mathrm{M}$ DTPA, $100 \mu \mathrm{M}$ butylated hydroxytoluene), snap frozen with liquid $\mathrm{N}_{2}$ and stored at $-80{ }^{\circ} \mathrm{C}$ under argon until used for analysis.

\subsection{Synthesis of lysine nitrile, $N^{\alpha}$-acetyl-2-aminoadipic acid, $N^{\alpha}$-acetyl- lysine nitrile}

Lysine nitrile (2-amino-5-cyanopentanoic acid) synthesis was carried out according to the method of Yamazaki [33] with modifications. Generally, NaOCl ( $4.5 \mathrm{mmol}$ ) was added to the stirring solution of $\mathrm{N}^{\alpha}$ Boc-L-Lysine ( $500 \mathrm{mg}, 2 \mathrm{mmol})$ in ethanol $(10 \mathrm{~mL})$. The mixture was stirred at room temperature for $24 \mathrm{~h}$. Afterwards, the reaction mixture was poured into $\mathrm{H}_{2} \mathrm{O}(50 \mathrm{~mL})$ and then was extracted with dichloromethane $\left(\mathrm{CH}_{2} \mathrm{Cl}_{2}, 3 \times 30 \mathrm{~mL}\right)$. The solution was concentrated by rotary evaporation and the residue purified on a silica gel column and eluted with $\mathrm{CH}_{2} \mathrm{Cl}_{2}$. The Boc blocking group was removed with a solution of $50 \%$ trifluoroacetic acid in $\mathrm{CH}_{2} \mathrm{Cl}_{2}$. The resultant lysine nitrile was analyzed by high resolution mass spectrometry (MS) and showed the anticipated elemental composition and fragmentation pattern. The theoretical exact mass to charge ratio $(\mathrm{m} / \mathrm{z})$ for LysCN $[\mathrm{MH}]^{+}\left(\mathrm{C}_{6} \mathrm{H}_{22} \mathrm{~N}_{2} \mathrm{O}_{2}\right)$ is 143.0821 au, the detected $\mathrm{m} / \mathrm{z}$ was $[\mathrm{MH}]^{+}=143.0820$ au, $\Delta \mathrm{ppm}=0.4$ au.

$\mathrm{N}^{\alpha}$-acetyl-2-aminoadipic acid (Ac-2AAA) was synthesized following the method of Ravindranath [34]. Due to the low solubility of 2-AAA in water, triethylamine (TEA) $(6 \mathrm{mmol})$ was added to $\mathrm{H}_{2} \mathrm{O}(2 \mathrm{~mL})$ to solubilize 2-AAA ( $320 \mathrm{mg}, 2 \mathrm{mmol})$. Acetic anhydride $(4 \mathrm{mmol})$ was then added and the mixture was sonicated for $30 \mathrm{~min}$ in an FS60 sonic water-bath (Fisher Scientific). This process was repeated after adding another aliquot of acetic anhydride (4 mmol). After sonication, the Ac2AAA was purified by reverse phase HPLC. The product was confirmed by high resolution MS analysis and showed the anticipated elemental composition and fragmentation pattern $\left(\mathrm{m} / \mathrm{z}[\mathrm{M}-\mathrm{H}]^{-}=202.0715 \mathrm{au}\right.$ and the theoretical exact mass $\left([\mathrm{M}-\mathrm{H}]^{-}\right)$of $\mathrm{Ac}-2 \mathrm{AAA}=202.0715 \mathrm{au}$, $\Delta \mathrm{ppm}=0.0 \mathrm{au}$ ).

$\mathrm{N}^{\alpha}$-acetyl-lysine nitrile (Ac-LysCN) was synthesized by adding $\mathrm{NaOCl}(5 \mathrm{mM})$ to $\mathrm{N}^{\alpha}$-Ac-Lys $(2 \mathrm{mM})$ in $50 \mathrm{mM}$ sodium phosphate, $\mathrm{pH}=7.0$. The solution was heated at $40{ }^{\circ} \mathrm{C}$ for $72 \mathrm{~h}$. Ac-LysCN was isolated from the solution by reverse phase HPLC and dried under reduced pressure in a vacuum centrifuge. The product was analyzed by 
high resolution MS and showed the anticipated elemental composition and fragmentation pattern $(m / z=183.0769$ au; theoretical exact mass $\left.[\mathrm{M}-\mathrm{H}]^{-}=183.0770 \mathrm{au}, \Delta \mathrm{ppm}=0.07 \mathrm{au}\right)$.

\subsection{High performance liquid chromatography for isolating $A c-2 A A A$ and Ac-LysCN}

HPLC separation of Ac-2AAA and Ac-LysCN were performed using preparative $\mathrm{C} 18$ columns $(10 \times 250 \mathrm{~mm}, 5 \mu \mathrm{m}$ particle diameter, Beckman, Ultrasphere ODS) pre-equilibrated with solvent A $(0.1 \%$ propionic acid in water, $\mathrm{pH}=3.3$ ). Products were monitored by absorbance $\left(\mathrm{A}_{205}\right)$ and eluted at a flow rate of $4 \mathrm{~mL} / \mathrm{min}$ with a nonlinear gradient generated with solvent $\mathrm{B}(0.1 \%$ acetic acid in methanol) as follows: $0-5 \%$ solvent $\mathrm{B}$ for $5 \mathrm{~min}$; $5-100 \%$ solvent $\mathrm{B}$ for $10 \mathrm{~min}$; isocratic $100 \%$ solvent $\mathrm{B}$ for $4 \mathrm{~min}$. The $\mathrm{pH}$ of the mobile phase was $\sim 2.0$. For solid phase extraction (SPE) we loaded the column with sample in $1 \% \mathrm{NH}_{4} \mathrm{OH}(\mathrm{pH}=11)$ and eluted with $1 \%$ formic acid $(\mathrm{pH}=2.7)$.

\subsection{Lysine nitrile stability test}

$1 \mathrm{mM}$ LysCN was incubated with either $6 \mathrm{~N} \mathrm{HCl}$ at $110{ }^{\circ} \mathrm{C}$ or $4 \mathrm{~N}$ $\mathrm{NaOH}$ at $120{ }^{\circ} \mathrm{C}$ in a sand bath. At the indicated times the reactions were cooled in an ice bath and then processed with strong anion exchange (SAX) solid phase extraction (SPE) and further analyzed by HPLC with online electrospray ionization tandem mass spectrometry (LC/MS/MS).

\subsection{Examining the mechanism of $N^{\alpha}$-Acetyl-L-Lysine oxidation by $\mathrm{HOCl}$}

Ac-Lys was used as the target for $\mathrm{HOCl}$ oxidation. Three different ratios of oxidant to target were used: $1 \mathrm{mM} \mathrm{HOCl}$ to $1 \mathrm{mM}$ Ac-Lys (1:1), $2 \mathrm{mM} \mathrm{HOCl}$ to $1 \mathrm{mM}$ Ac-Lys (2:1), and $1 \mathrm{mM} \mathrm{HOCl}$ to $1 \mathrm{M} \mathrm{(pH} \mathrm{7.0)} \mathrm{Ac-}$ Lys (1:1000). All of the oxidation reactions were performed in $50 \mathrm{mM}$ $\mathrm{PB}, \mathrm{pH}$ 7.0. The formation of monochloramine ( $\mathrm{RNHCl}$ ) and dichloramine $\left(\mathrm{RNCl}_{2}\right)$ intermediates were monitored by $\mathrm{UV}$ at $254 \mathrm{~nm}$ or $304 \mathrm{~nm}$, respectively [7]. The decay of $\mathrm{RNHCl}$ and $\mathrm{RNCl}_{2}$ was measured by HPLC with a photodiode array detector, by monitoring the absorbance $\left(\mathrm{A}_{254}\right.$ for $\mathrm{RNCl}$ and $\mathrm{A}_{304}$ for $\mathrm{RNCl}_{2}$ ). HPLC with on line triple-TOF mass spectrometry (AB Sciex tripleTOF 5600 system, Framingham, MA) was used to analyze and quantify Ac-Lys, Ac-2AAA and Ac-LysCN in the reaction. We used $\mathrm{N}$-acetyl-glutamic acid (Ac-Glu) as an internal standard and calibration curves were prepared using varying Ac2AAA and Ac-LysCN levels and a fixed amount of internal standard Ac-Glu. At the indicated times, internal standard $(20 \mu \mathrm{L}$ Ac-Glu, $100 \mu \mathrm{M})$ was mixed with $20 \mu \mathrm{L}$ reaction solution. A portion $(5 \mu \mathrm{L})$ of the mixture was injected onto a silica column $(2.0 \times 150 \mathrm{~mm}, 5 \mu \mathrm{m}$ particle, Phenomenex Luna silica) at a flow rate of $0.2 \mathrm{~mL} / \mathrm{min}$ with the following HPLC gradient: $100 \%$ solvent A $\left(0.1 \%\right.$ propionic acid in $\left.\mathrm{H}_{2} \mathrm{O}\right)$ for $5 \mathrm{~min}$; $0-100 \%$ solvent $\mathrm{B}$ ( $0.1 \%$ propionic acid in methanol) for $5 \mathrm{~min}$; isocratic a $100 \%$ solvent B for $3 \mathrm{~min}$; $100-0 \%$ solvent B for $2 \mathrm{~min}$; the column was then equilibrated with $100 \%$ A for $10 \mathrm{~min}$. The quantity of each analyte was measured by peak area corresponding to their exact mass relative to peak area of internal standard. TripleTOF MS was auto calibrated after every three injections.

In order to identify the proposed reaction intermediates, the TripleTOF mass spectrometer was set to simultaneously scan analytes with an exact mass to charge ratio from 100 to 1000 in the reaction, as well as the product ion of the identified compounds. The identities of the intermediates were confirmed by matching the exact mass of the precursor and the potential product ions with the proposed compounds, as well as their fragmentation patterns.

\subsection{Protein enzymatic digestion}

Protein samples were first dialyzed against $10 \mathrm{mM}$ Tris buffer,
$\mathrm{pH}=7.5$ prior to enzymatic digestion. The digestion ( $1 \mathrm{mg}$ protein/ $\mathrm{mL}$ ) was carried out in $0.1 \mathrm{M}$ Tris, $\mathrm{pH}=7.5$ and $10 \mathrm{mM} \mathrm{CaCl}_{2}$. To the reaction solutions we added stable isotope labeled internal standards $\left(\mathrm{d}_{3}\right.$-2-AAA, and $\left[{ }^{13} \mathrm{C}_{6},{ }^{15} \mathrm{~N}_{2}\right]$ Lys) prior to addition of protease. Samples were pre-warmed at $45{ }^{\circ} \mathrm{C}$ in a water bath and the digestion started with pronase addition (specific activity $=7 \mathrm{unit} / \mathrm{mg}$ ). The same amount of pronase $(50 \mu \mathrm{g} / \mathrm{mL})$ was added to the reaction every four hours to a final concentration of $300 \mu \mathrm{g} / \mathrm{mL}$ at the 20th hour. The digestion was stopped $24 \mathrm{~h}$ after the first addition of pronase by cooling on ice, and then by adding $2 \mathrm{~mL}$ of $1 \%$ ammonium hydroxide to the solution, followed by solid phase extraction (SPE) column chromatography. Digested samples were analyzed by LC/MS/MS following addition of internal standards.

\subsection{Quantification of protein lysine oxidation products after exposure to chlorinating oxidants}

Three different chlorinating oxidant systems were used: (i) reagent $\mathrm{HOCl}$; (ii) the $\mathrm{MPO} / \mathrm{H}_{2} \mathrm{O}_{2} / \mathrm{Cl}^{-}$system; (iii) and activated human neutrophils. Human serum albumin (HSA) $(1 \mathrm{mg} / \mathrm{mL}$ or $15 \mu \mathrm{M})$ was used as a source of protein for oxidation studies. $\mathrm{HOCl}$ or $\mathrm{H}_{2} \mathrm{O}_{2}$ (for the $\mathrm{MPO} / \mathrm{H}_{2} \mathrm{O}_{2} / \mathrm{Cl}^{-}$system) was used at molar ratios from $1 / 8$ to equal amount of protein target as indicated $(1.9-15 \mu \mathrm{M})$. When using the $\mathrm{MPO} / \mathrm{H}_{2} \mathrm{O}_{2} / \mathrm{Cl}^{-}$oxidation system, final reaction conditions included $32 \mathrm{nM}$ of isolated human MPO and $100 \mathrm{mM}$ of $\mathrm{Cl}^{-}$. For oxidation reactions using neutrophils, $1 \times 10^{6} / \mathrm{mL}$ isolated human neutrophils were incubated with HSA and, where indicated, activated by addition of $200 \mathrm{nM}$ (final) phorbol-12-myristate-13-acetate (PMA). Neutrophils were maintained in suspension at $37^{\circ} \mathrm{C}$ for $2 \mathrm{~h}$ by intermittent inversion. The media used was Hank's balance salt solution ( $\mathrm{pH}$ was 7.4, and the chloride concentration was approx. $140 \mathrm{mM}$ ). All reactions were terminated by adding $2 \mathrm{mM}$ methionine. After reaction, recovered HSA was placed in hydrolysis tubes, internal standards for mass spectrometry quantification were added, and then subjected to protease digestion for protein bound lysine, 2-AAA, and LysCN quantification by LC/MS/MS.

\subsection{Mouse inflammation model}

Age and sex-matched C57BL/6 J (wild type, WT) and MPO knockout (MPO-KO) mice (back-crossed > 50 generations onto C57BL/6 J) were used for peritonitis model studies [35]. Mice were intraperitoneally injected with $1 \mathrm{mM} 4 \%$ thioglycollate (TG) broth to recruit neutrophils. After twenty hours, the mice received a second intraperitoneal injection with zymosan $(250 \mathrm{mg} / \mathrm{kg})$. Four hours later peritoneal lavage was collected with PBS containing $100 \mu \mathrm{M}$ DTPA and $100 \mu \mathrm{M}$ butylated hydroxytoluene. In control groups, normal saline $(1 \mathrm{~mL})$ was injected intraperitoneally, and peritoneal lavage was collected after $24 \mathrm{~h}$. Lavage fluid was separated from cells by centrifugation at $800 \times g$ for $10 \mathrm{~min}$ at $4{ }^{\circ} \mathrm{C}$, overlaid with argon, and (both cells and supernatants) stored at $-80^{\circ} \mathrm{C}$ until analysis.

\subsection{Sample preparation for quantification of protein bound 2-AAA and LysCN}

After protease digestion, the sample mixture was diluted with $2 \mathrm{~mL}$ $1 \%$ ammonium hydroxide solution. This solution was passed over a mini SAX SPE cartridge $(3.0 \mathrm{~mL}, 25-35 \mu \mathrm{m}, 60 \mathrm{mg}$; Jordi lab), which was pre-equilibrated with $2 \times 2 \mathrm{~mL}$ methanol followed by $2 \times 2 \mathrm{~mL} 1 \%$ $\mathrm{NH}_{4} \mathrm{OH}$ solution. Columns were washed with $2 \times 2 \mathrm{~mL} \mathrm{H}_{2} \mathrm{O}$ and $2 \times 2 \mathrm{~mL} 70 \%$ methanol, and amino acids were eluted with $2 \times 2 \mathrm{~mL}$ $70 \%$ methanol supplemented with $1 \%$ formic acid. The eluted solution was dried under speed vacuum, and then reconstituted in $100 \mu \mathrm{L} \mathrm{H}_{2} \mathrm{O}$ for LC/MS/MS. 


\subsection{Sample preparation for quantification of free $2-A A A$ and $L y s C N$}

Ice cold methanol $(80 \mu \mathrm{L})$ containing $10 \mu \mathrm{M}\left[{ }^{13} \mathrm{C}_{6},{ }^{15} \mathrm{~N}_{2}\right]$ Lys (universally labeled lysine, u-Lys) and $1 \mu \mathrm{M} \mathrm{d}_{3}$-2AAA were added to $20 \mu \mathrm{L}$ mouse lavage fluid. The protein in the lavage was pelleted by centrifugation and the free amino acids in the supernatant were analyzed by LC/MS/MS.

\subsection{Mass spectrometry analyses}

Lysine, 2-AAA, and LysCN were quantified by LC/MS/MS. Calibration curves were prepared using varying concentrations of lysine, 2-AAA, and synthetic LysCN with a fixed amount of stable isotope-labeled internal standards $\left[{ }^{13} \mathrm{C}_{6},{ }^{15} \mathrm{~N}_{2}\right]$ Lys and $\mathrm{d}_{3}$-2-AAA respectively. Internal standards were added to each sample prior to sample preparation, which underwent enzymatic digestion and SAX solid phase extraction. The sample $(5 \mu \mathrm{L})$ was injected onto a silica column $(4.6 \times 250 \mathrm{~mm}$, Clipeus silica $5 \mu \mathrm{m}$, Higgins Analytical Inc, Mountain view, CA) at a flow rate of $0.8 \mathrm{~mL} / \mathrm{min}$. Separation was performed using the following gradient: start with solvent A $(0.1 \%$ propionic acid aqueous solution); $0-15 \%$ solvent B (methanol containing $0.1 \%$ acetic acid) for $10 \mathrm{~min}$; $15-100 \%$ solvent $B$ for $1 \mathrm{~min}$; isocratic with $100 \%$ solvent B for $3 \mathrm{~min}$; $0-100 \%$ solvent A for $1 \mathrm{~min}$; equilibration of the column with solvent A for $15 \mathrm{~min}$. After 3.9 min the HPLC column effluent was introduced into an API 4000 QTRAP mass spectrometer, and after $11 \mathrm{~min}$ the HPLC effluent was diverted to waste. The mass spectrometer was set to acquire data from $4 \mathrm{~min}$ to $10 \mathrm{~min}$. Analyses were performed using electrospray ionization in positive-ion mode with multiple reaction monitoring of characteristic precursor and product ions specific for the components monitored. The transitions monitored were mass-to-charge ratio $(\mathrm{m} / \mathrm{z}): 147 \rightarrow 84$ for lysine; $162 \rightarrow$ 98 , and $162 \rightarrow 55$ for 2 -AAA; $143 \rightarrow 97$, and $143 \rightarrow 54$ for LysCN, and $155 \rightarrow 90$ for $\left[{ }^{13} \mathrm{C}_{6},{ }^{15} \mathrm{~N}_{2}\right]$ Lys; and finally $165 \rightarrow 101$ for $\mathrm{d}_{3}$-2AAA.

\subsection{Statistical analysis}

The statistical significance of differences was determined using the Kruskal-Wallis test by ranks (one-way ANOVA on ranks) [36]. P values less than 0.05 were considered statistically significant.

\section{Results}

\subsection{Conventional acid or base protein hydrolysis methods convert LysCN into $2-A A A$}

As noted above, debate exists in the field of lysyl residue oxidation chemistry. Recent studies suggest LysCN may be the major stable posttranslational modification of lysine formed in vivo, based upon in vitro studies examining proteins exposed to excess HOCl [18]. We therefore first sought to investigate whether prior studies used protein hydrolysis methods that would accurately measure LysCN and 2-AAA in tissues. LysCN was synthesized as outlined under Materials and Methods and both its stability and the stability of 2-AAA examined during typical protein hydrolysis conditions (either $6 \mathrm{~N} \mathrm{HCl}, 110{ }^{\circ} \mathrm{C}$; or $4 \mathrm{~N} \mathrm{NaOH}, 120^{\circ} \mathrm{C}$ ). Of note, LysCN was virtually quantitatively converted into 2-AAA under both acid and base hydrolysis conditions (Fig. $1 A$ and $B$ ). Thus, typical protein hydrolysis conditions are not appropriate to accurately quantify either protein-bound LysCN or 2AAA in biological samples. These results also suggested that ours and others' previously published studies used conditions during sample preparation (e.g. Refs. [3,11-14]) that may have inadvertently overestimated the 2-AAA content because a portion (or all) of the measured 2-AAA may have come from the hydrolysis of LysCN, if it is present in the sample. Of further note, however, as far as we are aware, no studies to date have reported detection of protein-bound LysCN in vivo.

\subsection{Quantification of 2-AAA and LysCN in biological samples}

To address the issue of LysCN conversion to 2-AAA during sample preparation we used enzymatic proteolytic digestion to break down the protein into its constituent amino acids under conditions where both 2AAA and LysCN are stable. Subsequently, we developed a mass spectrometry (MS)-based assay to accurately quantify both 2-AAA and LysCN in biological samples. For complete proteolytic digestion of proteins extracted from tissue or plasma we used a series of small amounts (relative to target protein mass) of pronase, a mixture of proteases from Streptomyces griseus, to break the peptide bonds releasing free amino acids (see Materials and m ethods). We validated the efficiency of the pronase proteolytic method employed by comparing the digestion yield of various amino acids against conventional acid hydrolysis of the same amount of human serum albumin (HSA) or precipitated plasma protein. We considered $\mathrm{HCl}$ hydrolysis as complete, and defined pronase proteolytic efficiency as the ratio of amino acid amounts recovered from pronase digestion to acid hydrolysis. We eliminated contributions from pronase self-digestion by including control studies with every batch to allow subtraction of amino acid amounts recovered in parallel pronase self-digestion reactions (also ensuring amino acids monitored and subtracted were less than $10 \%$ total observed in complete reaction samples under the conditions employed). Our control studies revealed that under the methods employed, the overall recovery yield of various amino acids was in excess of 90\%: (e.g. Met $91 \pm 1 \%$, Lys $95 \pm 1 \%$, Phe $94 \pm 3 \%$, Tyr 91 $\pm 2 \%$, Leu $93 \pm 3 \%$, Arg $93 \pm 3 \%$, Val $97 \pm 2 \%$ ). An accurate recovery estimate for Trp could not be obtained because there is only one Trp residue in HSA, and the self (pronase) enzyme digestion under the conditions employed was observed to contribute $>10 \%$ to the Trp pool. Additional control studies exposing LysCN and 2-AAA to the same proteolytic conditions showed that both compounds are stable with 99 $\pm 2 \%$ and $102 \pm 4 \%$ recovery, respectively.

\subsection{The mechanism of $N^{\alpha}$-protected lysyl residue oxidation by $\mathrm{HOCl}$}

To understand the chemistry and clarify the products of posttranslational modification of protein lysyl residues by MPO, we initially investigated lysine oxidation by the major MPO-generated oxidant, HOCl. In these initial mechanistic studies we used $\mathrm{N}^{\alpha}$-acetyl-lysine (AcLys) as a protein lysyl residue surrogate. The acetyl group was used to protect the $\alpha$-amine group of lysine from oxidation and to mimic the peptide bond. Following the reaction of $\mathrm{N}^{\alpha}$-Ac-Lys with $\mathrm{HOCl}$, we discovered that both $\mathrm{N}^{\alpha}$-acetyl-2-aminoadipic acid (Ac-2AAA) and $\mathrm{N}^{\alpha}$ acetyl-lysine nitrile (Ac-LysCN) were formed. Moreover, we determined that Ac-2AAA is the major oxidation product in this reaction when a lower molar ratio of HOCl: Ac-Lys is used, whereas at higher oxidant to target exposures, the amount of Ac-LysCN increases and becomes the major product (Figs. 2-4). Previous work has already established that the reaction of $\mathrm{HOCl}$ with the backbone $\alpha$-amino group of free amino acids and side chain amino groups produce chloramine reaction intermediates [24,25,37-39]. Our results suggest that Ac-2AAA is produced through a monochloramine reaction intermediate, while AcLysCN might be formed through a dichloramine intermediate hypotheses subsequently confirmed in our studies (see below).

We first examined both the stoichiometry and time course of reaction products formed during interaction of Ac-Lys with $\mathrm{HOCl}$ as described under Materials and methods. Results at $1 \mathrm{~mol}$ oxidant (HOCl) to $1 \mathrm{~mol}$ target $\left(\mathrm{N}^{\alpha}\right.$-Ac-Lys) are shown in Fig. 2. Consistent with previous studies showing that the $\varepsilon$-amine group of lysine readily reacts with $\mathrm{HOCl}$ forming $\mathrm{N}^{\alpha}$-Ac- $\mathrm{N}^{\varepsilon}$-chloro-lysine (RNHCl) [7,24,3841], we observed that Ac-Lys was rapidly consumed, and an intermediate, RNHCl absorbing at $254 \mathrm{~nm}$, forms and then decays (Fig. 2). Monitoring the reaction using high-pressure liquid chromatography (HPLC) coupled with both a photodiode array detector and mass spectrometry analyses revealed that $\mathrm{RNHCl}$ decays into a longer-lived 
A $6 \mathrm{M} \mathrm{HCl} 110^{\circ} \mathrm{C}$ hydrolysis

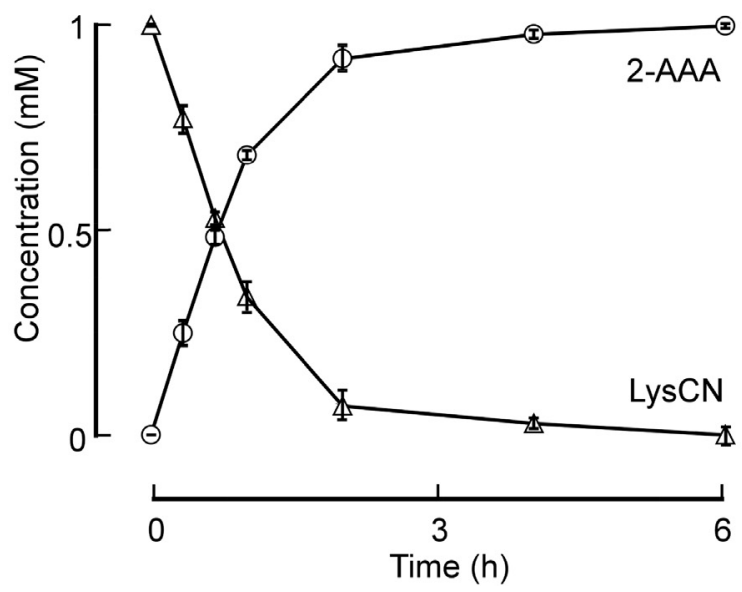

B $4 \mathrm{M} \mathrm{NaOH} 120^{\circ} \mathrm{C}$ hydrolysis

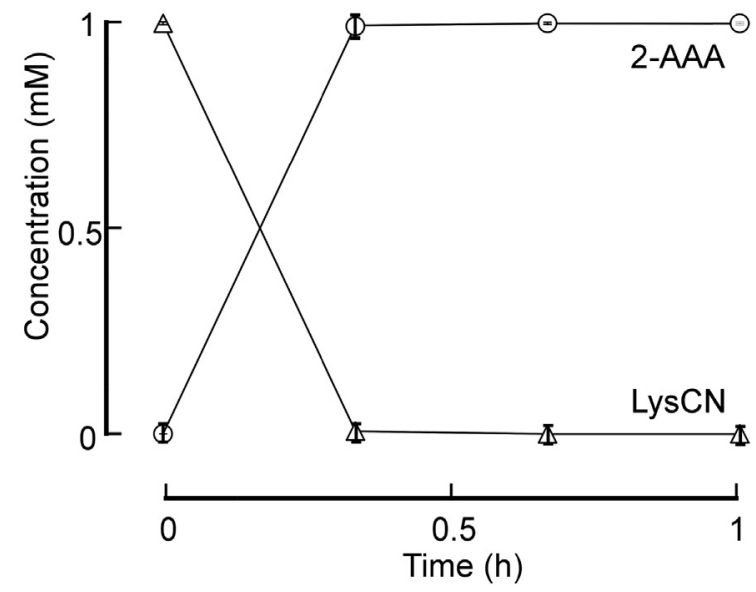

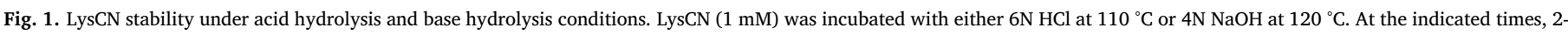

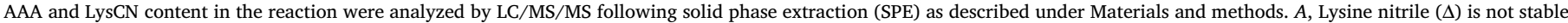

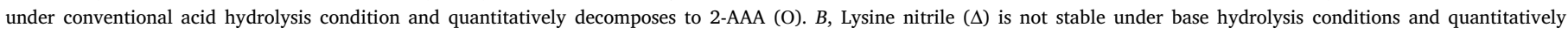
decomposes to 2-AAA (O). Data shown represent the mean $+/-$ S.D. of duplicated determinations for a study performed greater than three independent times.

$\mathrm{HOCl}: \mathrm{N}^{\alpha}$-Ac-Lys

$1: 1$

$\mathrm{HOCl} \quad \mathrm{N} \alpha-\mathrm{Ac}-\mathrm{Lys}-\mathrm{NHCl}$

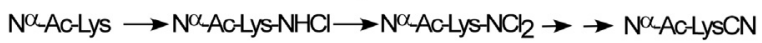

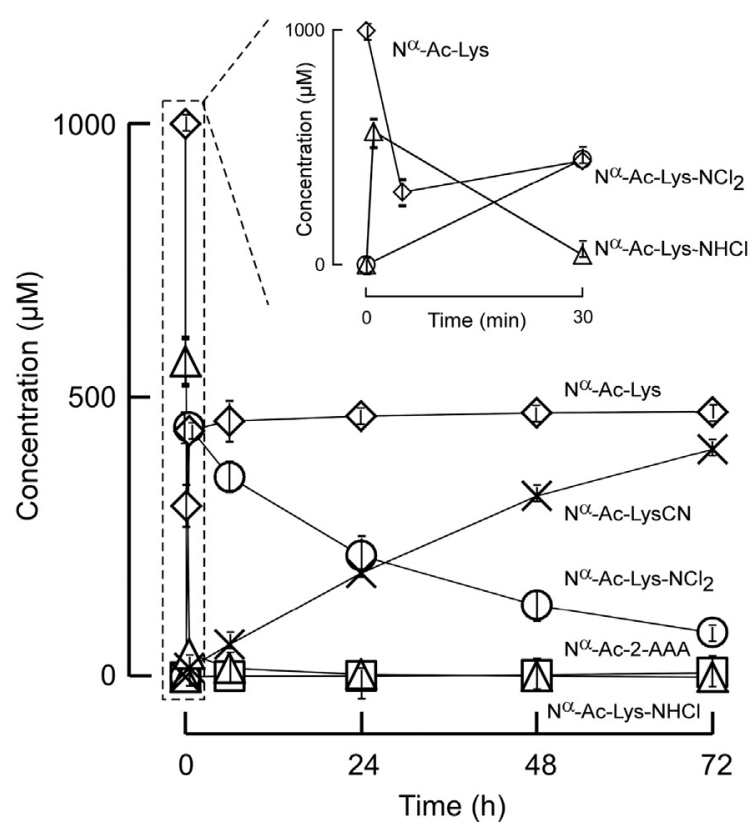

Fig. 2. $\mathrm{N}^{\alpha}$-acetyl-LysCN is the major product in the reaction of $\mathrm{N}^{\alpha}$-acetyl-lysine with equal moles of $\mathrm{HOCl}$. $\mathrm{HOCl}(1 \mathrm{mM})$ was added to $\mathrm{N}^{\alpha}$-acetyl-lysine $(1 \mathrm{mM})$ in reaction buffer (see Materials and methods for details). Initial $\mathrm{N}^{\alpha}$-acetyl-lys- $\mathrm{NHCl}(\Delta)$ production was monitored by UV $254 \mathrm{~nm}$. $\mathrm{N}^{\alpha}$-acetyl-lys- $\mathrm{NCl}_{2}(\mathrm{O})$ decay was measured by HPLC-UV at $304 \mathrm{~nm}$. All analyte identities (including mono- and di-chloramines) were confirmed by high resolution mass spectrometry analyses. $\mathrm{N}^{\alpha}$-acetyl-lys $(\diamond), \mathrm{N}^{\alpha}$-acetyl-lysCN $(\times), \mathrm{N}^{\alpha}$ acetyl-2-AAA $(\square)$ were quantified by LC-Triple-TOF mass spectrometer as described under Materials and methods. Data shown represent the mean $+/-$ S.D. of duplicated determinations for a study performed greater than three independent times.

intermediate, $\mathrm{N}^{\alpha}$-Ac- $\mathrm{N}^{\varepsilon}$-dichloro-lysine $\left(\mathrm{RNCl}_{2}\right)$ that absorbs at $304 \mathrm{~nm}$. Furthermore, separate studies starting with $\mathrm{RNHCl}$ and mass spectrometry (MS) analyses indicated rapid formation of Ac-Lys and $\mathrm{RNCl}_{2}$, consistent with a disproportionation reaction of $\mathrm{RNHCl}$ [42]. Ultimately, $\mathrm{RNCl}_{2}$ decays too as the reaction proceeds [37], leading

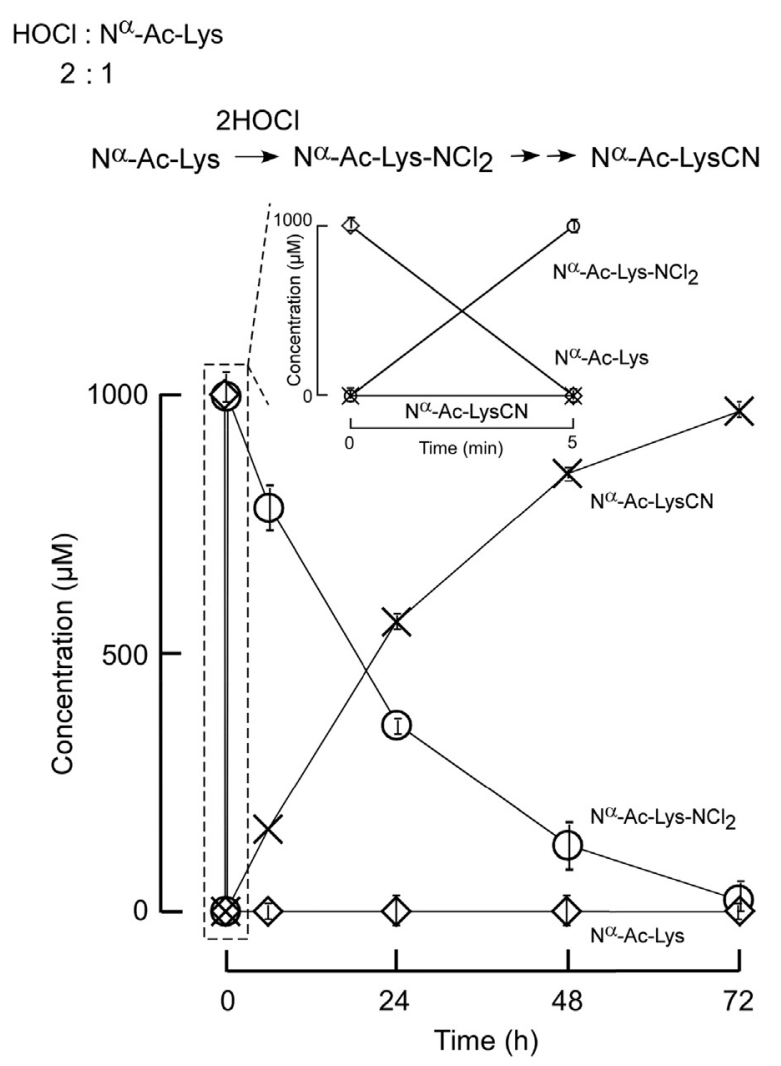

Fig. 3. $\mathrm{N}^{\alpha}$-acetyl-LysCN is the major product in the reaction of $\mathrm{N}^{\alpha}$-acetyl-lysine with $2 \mathrm{~mol}$ of $\mathrm{HOCl}$. $\mathrm{N}^{\alpha}$-acetyl-lysine $(1 \mathrm{mM})$ was incubated with $\mathrm{HOCl}(2 \mathrm{mM})$ in reaction buffer and reaction products formed monitored as described in Materials and methods. All analyte identities (including di-chloramine) were confirmed by high resolution mass spectrometry analyses. $\mathrm{N}^{\alpha}$-acetyl-lys- $\mathrm{NCl}_{2}(\mathrm{O})$ decay was measured by $\mathrm{UV}$ at $304 \mathrm{~nm} . \mathrm{N}^{\alpha}$ acetyl-lys $(\diamond), \mathrm{N}^{\alpha}$-acetyl-lysCN $(\times)$, were quantified by LC-Triple-TOF mass spectrometer. Data shown represent the mean $+/$ - S.D. of duplicated determinations for a study performed greater than three independent times.

to Ac-LysCN as the main product and a small amount of Ac-2AAA (Fig. 2). When the oxidant to Ac-Lys ratio is increased to 2:1 (HOCl: $\mathrm{N}^{\alpha}$ Ac-Lys; Fig. 3), Ac-Lys is completely consumed shortly after adding HOCl rapidly forming the dichloramine [37], which then further decomposes into Ac-LysCN.

Lysine is one of the most abundant amino acids in proteins (about 1 


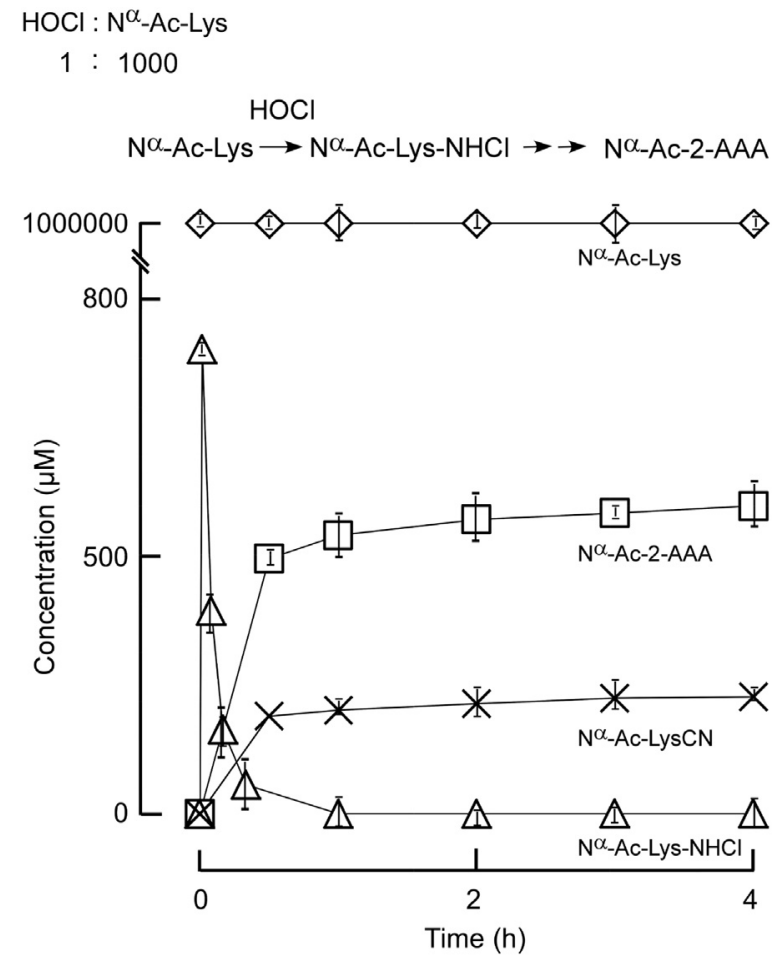

Fig. 4. $\mathrm{N}^{\alpha}$-acetyl-2-AAA is the major product in the reaction of $\mathrm{N}^{\alpha}$-acetyl-lysine with HOCl (1000:1 M ratio). HOCl $(1 \mathrm{mM})$ was reacted with $\mathrm{N}^{\alpha}$-acetyL-lysine $(1 \mathrm{M})$. The reactions were performed in reaction buffer as described in Materials and m ethods. All analyte identities (including mono-chloramine) were confirmed by high resolution mass spectrometry analyses. $\mathrm{N}^{\alpha}$-acetyl-lys- $\mathrm{NHCl}(\mathrm{O})$ decay was measured by $\mathrm{UV}$ at $254 \mathrm{~nm}$. $\mathrm{N}^{\alpha}$ acetyl-lysCN $(\Delta), \mathrm{N}^{\alpha}$-acetyl-2-AAA $(\square)$ were quantified by LC-Triple-TOF mass spectrometer. Data shown represent the mean $+/-$ S.D. of duplicated determinations for a study performed greater than three independent times.

in 5 residues), but under physiological conditions the amount of oxidant produced by MPO is typically much less than the amount of lysine. At sites of inflammation one would expect monochloramines to be rapidly scavenged by free and protein-bound thiol [43-45]. This is because methionine and cysteine preferentially react with $\mathrm{HOCl}$ orders of magnitude faster than lysine $[24,46]$. Therefore it is reasonable to assume that under physiological conditions the molar concentration of MPO-generated oxidants will be orders of magnitude less than that of lysine ride chains (especially in the extracellular compartment). Thus, we performed studies where the oxidant is present at only a trace level relative to protein target ratio (e.g. 1:1000, HOCl: $\mathrm{N}^{\alpha}$-Ac-Lys), as one might predict exist in vivo (Fig. 4). Here, the initial RNHCl formed was observed to decompose into 2-AAA as the major product, and LysCN as a minor product (Fig. 4). Also observed under these conditions, the monochloramine intermediate formed is at low level relative to unreacted Ac-Lys, and the $\mathrm{RNHCl}$ disproportionation reaction (forming $\mathrm{RNCl}_{2}$ ) does not significantly occur.

Based on these results we hypothesized that when Ac-Lys is in a large molar excess with respect to the oxidant species, Ac-Lys-NHCl takes a different reaction pathway by eliminating $\mathrm{HCl}$ with the formation of an imine intermediate instead of disproportionation. The imine compound would be relatively unstable and further hydrolyze, releasing ammonia to form $\mathrm{N}^{\alpha}$-acetyl-2-aminoadipic- $\delta$-semialdehyde, which similarly is unstable and reactive in the presence of $\mathrm{RNHCl}$ (or $\mathrm{HOCl}$ ) and could be further oxidized to Ac-2AAA. This reaction pathway has been established for the reaction of $\mathrm{HOCl}$ with the $\alpha$-amino groups of free amino acids, but here we were able to directly test whether this pathway is plausible also for the $\varepsilon$-amino group of lysine by using high resolution mass spectrometry (see Materials and methods). Both proposed imine and semialdehyde intermediates were identified as sequential products formed in the oxidation reaction.
The MS/MS spectra of the two detected molecules (Fig. 5A and $B$ ) indicate that these two compounds have identical anticipated elemental composition and fragmentation patterns as the expected imine and semialdehyde intermediates. For example, the measured masses of the parents and their fragment ions (see Fig. $5 A$ and $B$ for proposed fragmentation pattern) are all less than $2 \mathrm{ppm}$ from the theoretical masses, strongly supporting the identity of these proposed labile intermediates. The existence of these two compounds in the oxidation reaction strongly supports our proposed pathway for Ac-2AAA formation.

\subsection{Human serum albumin lysyl residue oxidation by HOCl and the MPO/ $\mathrm{H}_{2} \mathrm{O}_{2} / \mathrm{Cl}^{-}$system}

Next we used human serum albumin (HSA) as a target protein model system to further investigate lysine oxidation by $\mathrm{HOCl}$ or mediated via the action of human MPO (Fig. 6).

Initially, we used a range of HOCl: HSA molar ratios 0-1; HSA $1 \mathrm{mg} /$ $\mathrm{mL}(15 \mu \mathrm{mol}), \mathrm{HOCl} 0-15 \mu \mathrm{mol})$ and observed results similar to those observed with Ac-Lys oxidation (Fig. 6A) - namely, at a low molar ratio of oxidant to target ( $<0.3$ ), 2-AAA is the major oxidation product (the yield of 2-AAA is approx. $1 \%$ of the $\mathrm{HOCl}$ added) of the stable end products of lysine oxidation monitored, while LysCN becomes the major product at a higher molar ratio (the yield of LysCN is approx. $1.3 \%$ of the added $\mathrm{HOCl}$ ). Nearly identical results were obtained with the complete $\mathrm{MPO} / \mathrm{H}_{2} \mathrm{O}_{2} / \mathrm{Cl}^{-}$system (Fig. $6 \mathrm{~B}$ ). In additional control studies, we confirmed that each component of the $\mathrm{MPO} / \mathrm{H}_{2} \mathrm{O}_{2} / \mathrm{Cl}^{-}$system is required for HSA lysine oxidation to produce protein-bound 2-AAA and LysCN $\left(\mathrm{H}_{2} \mathrm{O}_{2}\right.$ : $\mathrm{HSA}=0.25$, Fig. 7).

\subsection{Human neutrophils oxidize protein lysyl residues forming both 2-AAA (major) and LysCN (minor) as products}

MPO is one of the most abundant proteins in neutrophils $[4,47]$. During neutrophil activation at sites of inflammation, MPO is released and uses $\mathrm{H}_{2} \mathrm{O}_{2}$ from respiratory bursts and physiological levels of chloride to make $\mathrm{HOCl}[4,47]$. We therefore next sought to test whether activated isolated human neutrophils can employ the MPO system to oxidize protein lysyl residues and generate 2-AAA and LysCN. HSA was incubated with human neutrophils in the presence of media containing physiological levels of chloride followed by PMA stimulation to activate the neutrophils. DTPA $(100 \mu \mathrm{mol})$ was also added to the media to inhibit potential free redox active transition metal ion metal-catalyzed oxidation. In the presence of this "Complete System" (i.e. HSA, neutrophils, and PMA), both protein-bound 2-AAA and LysCN were formed with 2-AAA as the major product (Fig. 8). On the other hand, in the absence of any one of the components of the oxidation system (neutrophils, or PMA) or in the presence of an MPO inhibitor (e.g. azide), no significant amount of oxidation products were observed. Addition of catalase, a scavenger of $\mathrm{H}_{2} \mathrm{O}_{2}$, dramatically reduced the production of both 2-AAA and LysCN, and addition of methionine, a scavenger of HOCl $[24,48,49]$, also diminished both 2-AAA and LysCN formation, consistent with neutrophils employing the $\mathrm{MPO} / \mathrm{H}_{2} \mathrm{O}_{2} / \mathrm{Cl}^{-}$ system in generation of these post translational modifications of lysine (Fig. 8).

\subsection{MPO forms 2-AAA and LysCN in vivo at sites of inflammation}

We further investigated whether MPO is involved in the formation of 2-AAA and LysCN at sites of inflammation in vivo. For these studies we used MPO-KO mice and an acute inflammation model, zymosaninduced peritonitis, that is well characterized and frequently employed to gauge the role of MPO in protein or lipid oxidation in vivo [35]. As shown in Fig. 9A, the content of 2-AAA in peritoneal lavage protein from wild type mice significantly $(P<0.001)$ increases following thioglycolate (TG)-induced recruitment of leukocytes and zymosan 

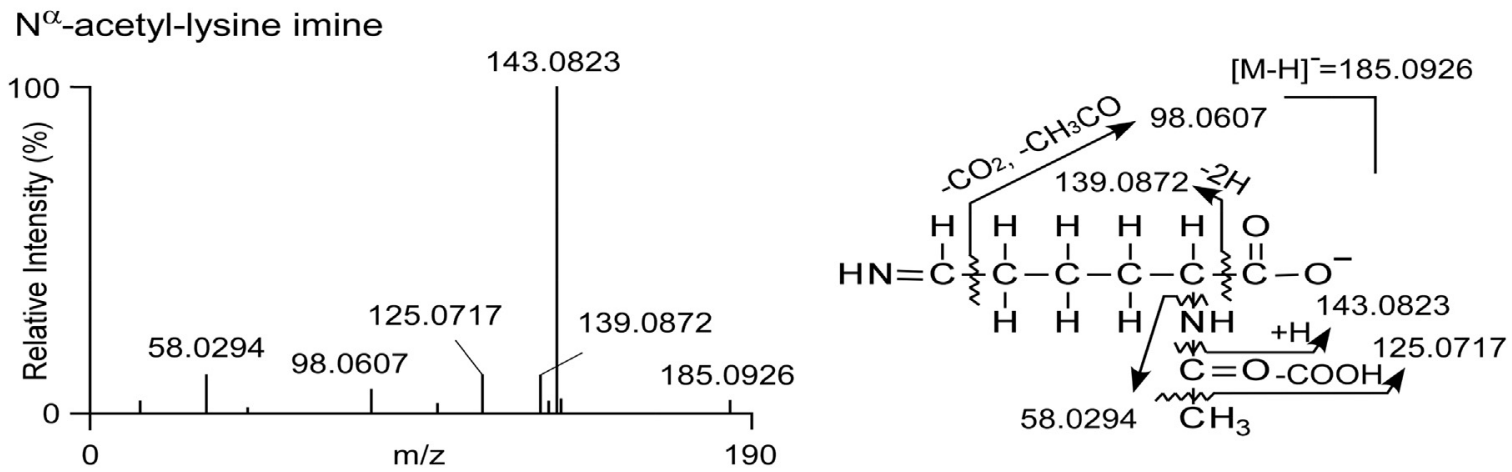

B

$\mathrm{N}^{\alpha}$-acetyl-2-aminoadipic semialdehyde
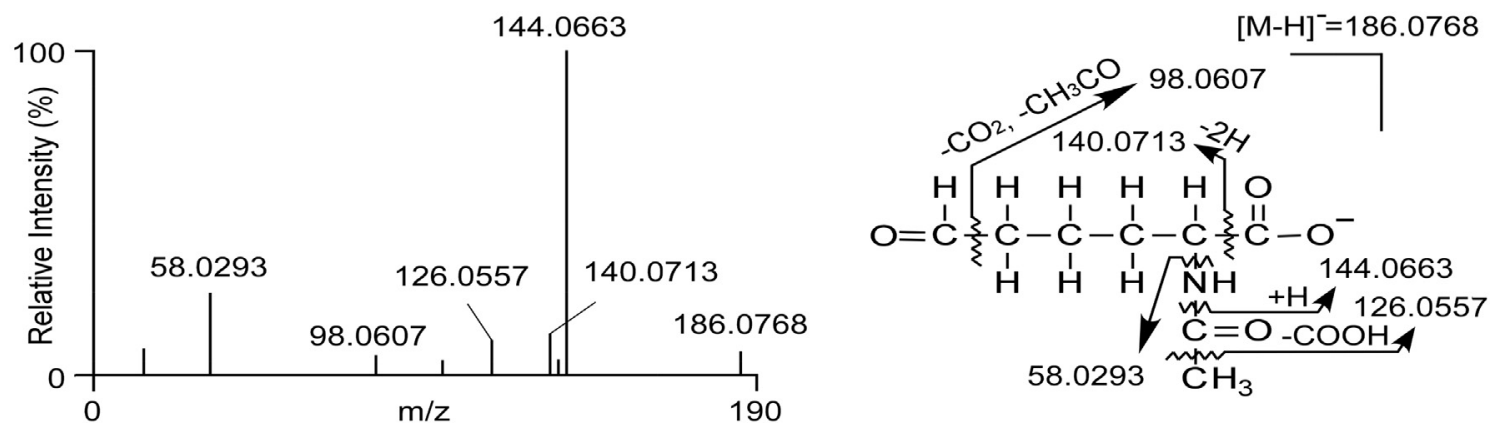

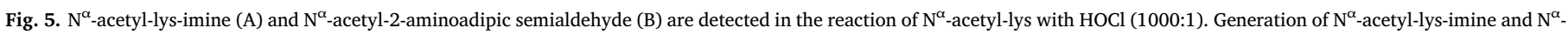

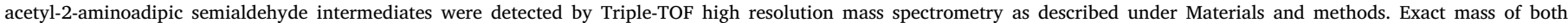
precursor and product ions of the identified molecules match with those of the calculated masses of the proposed reaction intermediates as shown, respectively.

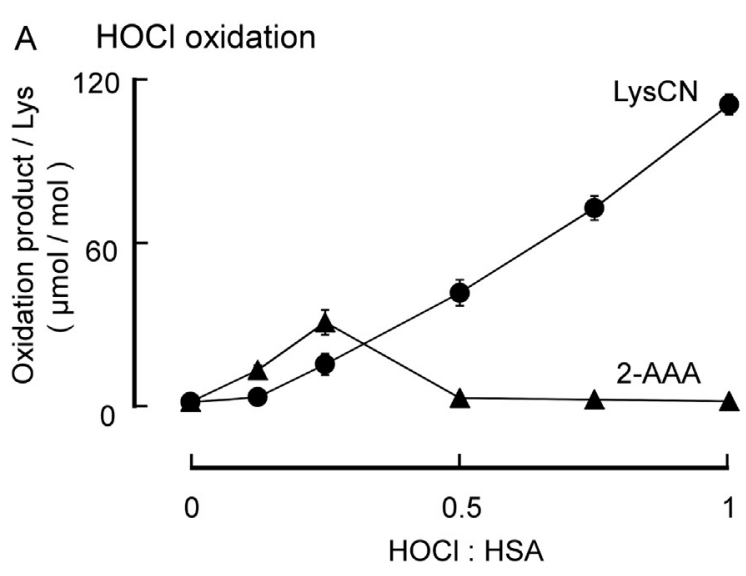

B $\mathrm{MPO} / \mathrm{H} 2 \mathrm{O} 2 / \mathrm{Cl}$ oxidation

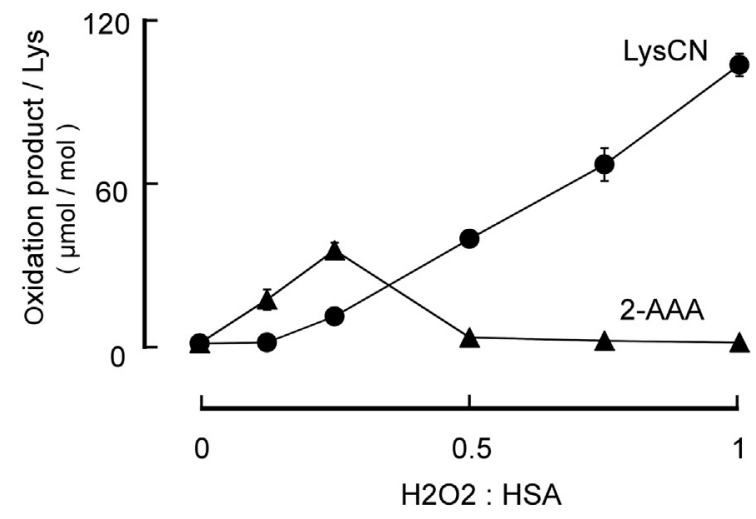

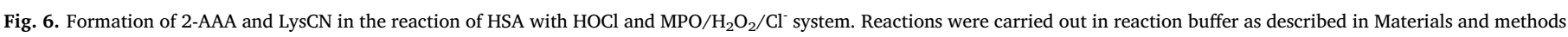

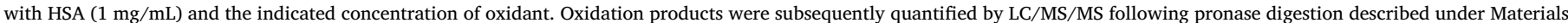

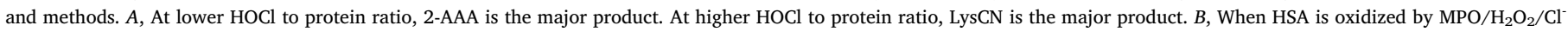

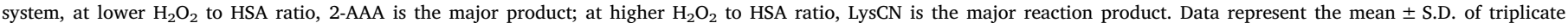
determinations for an experiment performed at least 3 separate times.

(ZM) triggered leukocyte activation in WT mice. In sharp contrast, however, the MPO-KO mice showed no significant increase in 2-AAA following TG and ZM injection. Similarly, a significant increase in protein-bound LysCN is formed in WT mice injected with TG and ZM (P $<0.001$ ), but not in MPO-KO mice (Fig. 9B). Moreover, while at baseline similar protein content of 2-AAA and LysCN in peritoneal lavage proteins were noted, the amount of LysCN produced during inflammation was approximately half that observed for 2-AAA.

\subsection{MPO oxidation is a source of free 2-AAA production in vivo}

We also examined whether MPO can generate free 2-AAA in vivo. Here peritoneal lavage supernatants were analyzed for quantification of free 2-AAA and free LysCN. As shown in Fig. 10, after neutrophils were elicited by TG and activated by ZM, there was a significant $\sim 4.5$-fold increase $(\mathrm{p}<0.001)$ in free 2-AAA noted in WT mice over TG treatment alone. This increase was completely abrogated in MPO-KO mice. Attempts to measure free LysCN in the lavage fluid failed to demon- 
$\mathrm{H} 2 \mathrm{O} 2: \mathrm{HSA}$

$0.25: 1$

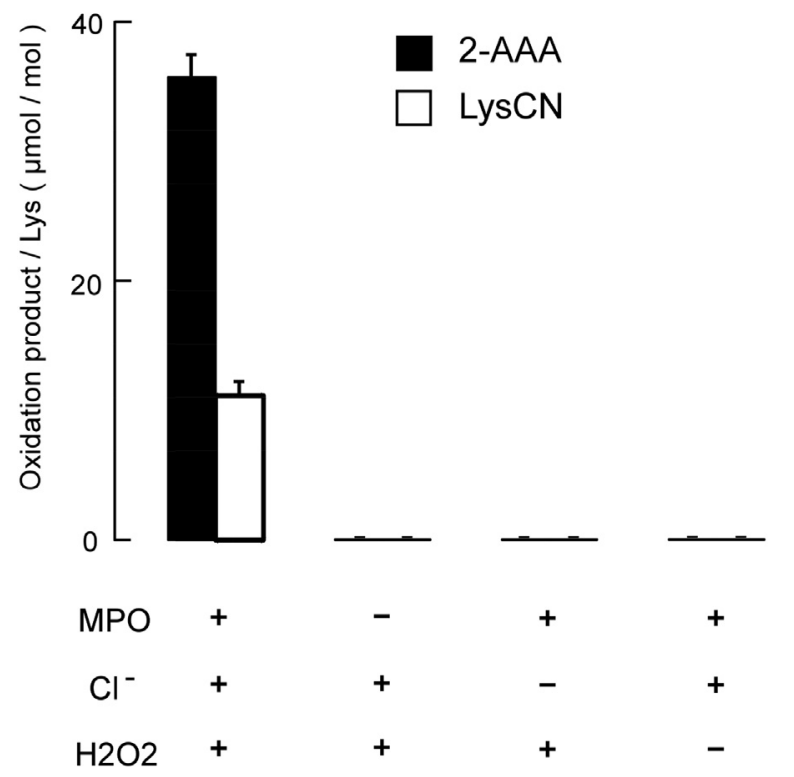

Fig. 7. Protein bound 2-AAA and LysCN formation requires protein lysyl residue exposure to the complete $\mathrm{MPO} / \mathrm{H}_{2} \mathrm{O}_{2} / \mathrm{Cl}^{-}$system. HSA $(1 \mathrm{mg} / \mathrm{mL}, 15 \mu \mathrm{M})$ was exposed to the complete MPO $/ \mathrm{H}_{2} \mathrm{O}_{2} / \mathrm{Cl}^{-}$system, or to the indicated components of the MPO system. The production of 2-AAA LysCN and oxidation precursor lysine were quantified by LC/MS/MS as described in Materials and methods. Only under the complete $\mathrm{MPO} / \mathrm{H}_{2} \mathrm{O}_{2} / \mathrm{Cl}^{-}$system, 2 -AAA and LysCN were produced. Data values represent the mean \pm S.D. of triplicate samples for an experiment performed at least 3 separate times.

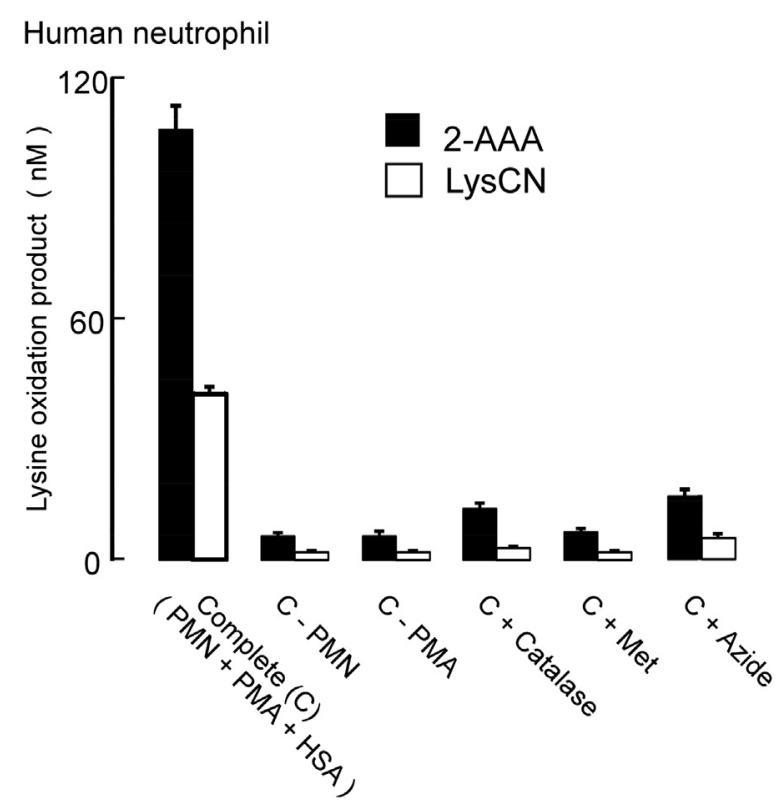

Fig. 8. Activated human neutrophils employ the $\mathrm{MPO} / \mathrm{H}_{2} \mathrm{O}_{2} / \mathrm{Cl}^{-}$system to oxidize protein bound lysyl residues to 2-AAA and LysCN. The complete MPO system ( C) consisted of freshly harvested human neutrophils (PMN) $\left(1 \times 10^{6}\right.$ cells $\left./ \mathrm{mL}\right)$ activated with $200 \mathrm{nM}$ phorbol myristate acetate (PMA) in the presence of HSA $(1 \mathrm{mg} / \mathrm{mL})$. Where indicated, either PMN or PMA was omitted; or catalase $(20 \mu \mathrm{g} / \mathrm{mL})$ or methionine $(2 \mathrm{mM})$ was included with the complete MPO system. Results are the mean \pm S.D. of triplicate determinations for an experiment performed at least 3 separate times. strate any detectable levels in response to any of the treatments. Under the conditions employed for the assay, the limit of detection ( $\mathrm{S} / \mathrm{N}$ of peak $=3: 1$ ) of LysCN was $40 \mathrm{nM}$.

\subsection{Human aortic lesions are enriched in both 2-AAA and LysCN}

In the final series of studies we sought to test whether 2-AAA and LysCN are present in normal human aorta and whether levels of these oxidation products are enriched in aortic atherosclerotic lesions. Using the validated pronase digestion method we readily detected both species and observed the content of both protein-bound 2-AAA and LysCN are elevated in human aortic atherosclerotic plaque compared to healthy aorta. Fig. $11 A$ and $B$ shows that protein bound 2-AAA and LysCN content in atherosclerotic lesions are significantly higher $(\sim 2$ fold, $\mathrm{p}<0.001$ ) than in normal aortic tissue; moreover, the 2-AAA content in human aortic tissues observed were more than 10-fold higher $(\mathrm{p}<0.005)$ than that for LysCN.

\section{Discussion}

Our present studies explore the chemistry and the stable terminal products of protein lysyl residue oxidation by MPO generated chlorinating oxidants in vitro and in vivo. We provide direct evidence that both 2-AAA and LysCN are posttranslational modifications of protein lysyl residues through action of MPO-generated oxidants in vivo. Moreover, detailed analysis of the reaction mechanism reveals the following scheme summarized in Fig. 12. First, activated neutrophils or monocytes generate $\mathrm{HOCl}$, which reacts with the $\varepsilon$-amino group of protein lysine to produce a $\mathrm{N}^{\varepsilon}-$ monochloramine as a reaction intermediate [37]. The monochloramine is labile, and can further decompose to form 2-AAA. We suggest that because there is still chlorinating oxidant capacity of lysine monochloramine, in the presence of excess protein lysines, as long as it does not get scavenged (e.g. by RSH or RSR groups) it keeps exchanging halogen to other lysine $\mathrm{N}^{\varepsilon}$-amine residues reforming $\mathrm{N}^{\varepsilon}-$ monochloramine until it eliminates $\mathrm{HCl}$, forming an imine intermediate. The latter undergoes subsequent hydrolysis through the elimination of $\mathrm{NH}_{3}$ and addition of $\mathrm{H}_{2} \mathrm{O}$ to give the 2aminoadipate $-\delta$-semialdehyde intermediate (Fig. 12).

The semialdehyde intermediate is not stable and rapidly forms 2AAA. Importantly, we were able to directly detect both the indicated imine and semialdehyde intermediates in the reaction mixture by high resolution MS, as well as to show direct precursor $\rightarrow$ product relationships for most of the proposed transitions indicated including starting from isolated mono-chloramine, further supporting the pathway proposed for the formation of 2-AAA. Our studies further revealed that when the oxidant to lysine target ratio is higher, the $\mathrm{RNHCl}$ formed can either disproportionate to produce dichloramine $\mathrm{RNCl}_{2}$ intermediate +lysine, or further react with another $\mathrm{HOCl}$ molecule to form the dichloramine $\mathrm{RNCl}_{2}$ intermediate [37]. This latter intermediate was isolated and shown to directly decompose into LysCN. Collectively, our results also help to explain why the prior in vitro study by Sivey et al. $[18,50,51]$ reported LysCN as the overwhelming product formed without 2-AAA. Our studies show similar results when a comparable vast molar excess of oxidant is used ( $\sim 100$-fold or more relative to target). Further, quantitation of each of the products formed under different molar ratios of oxidant to target (Figs. 2-4) is entirely consistent with the stoichiometry of the reactions shown in Fig. 12. It is of interest to note that in previous studies we demonstrated that chlorine gas $\left(\mathrm{Cl}_{2}\right)$ can be produced by the $\mathrm{MPO} / \mathrm{H}_{2} \mathrm{O}_{2} / \mathrm{Cl}^{-}$system of neutrophils [9]. $\mathrm{Cl}_{2}$ is in equilibrium with $\mathrm{HOCl}$ in water and was directly detected by mass spectrometry in headspace gas above activated neutrophils [9]. We therefore include the hypothetical pathway involving $\mathrm{Cl}_{2}$ reaction with protein lysyl residues leading directly to lysine monochloramine and dichloramine derivatives as yet another possible pathway envisioned at high ratios of oxidant to target protein $\mathrm{N}^{\varepsilon}$ - Lys groups for generation of LysCN (Fig. 12). 
A PB-2-AAA in peritoneal lavage supernatant

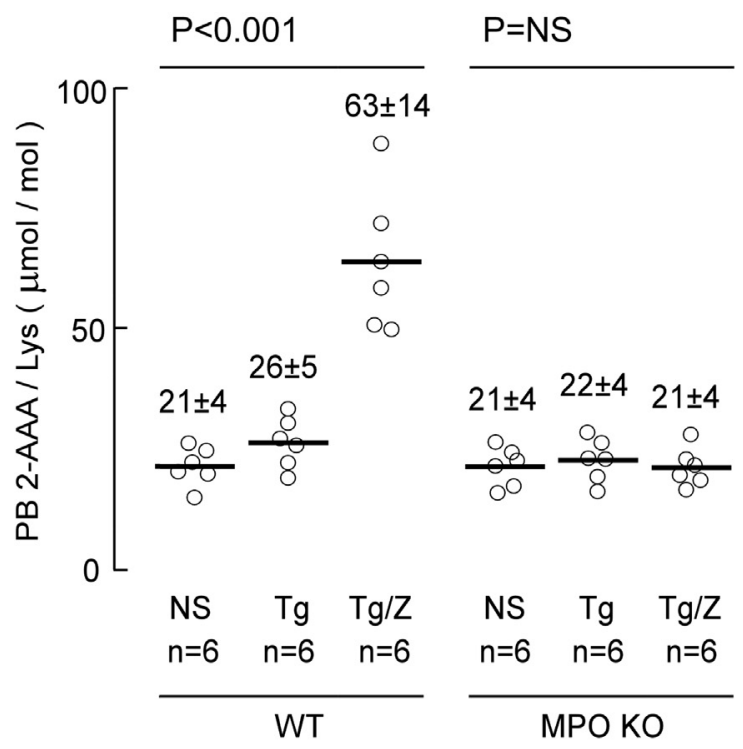

B PB-LysCN in peritoneal lavage supernatant

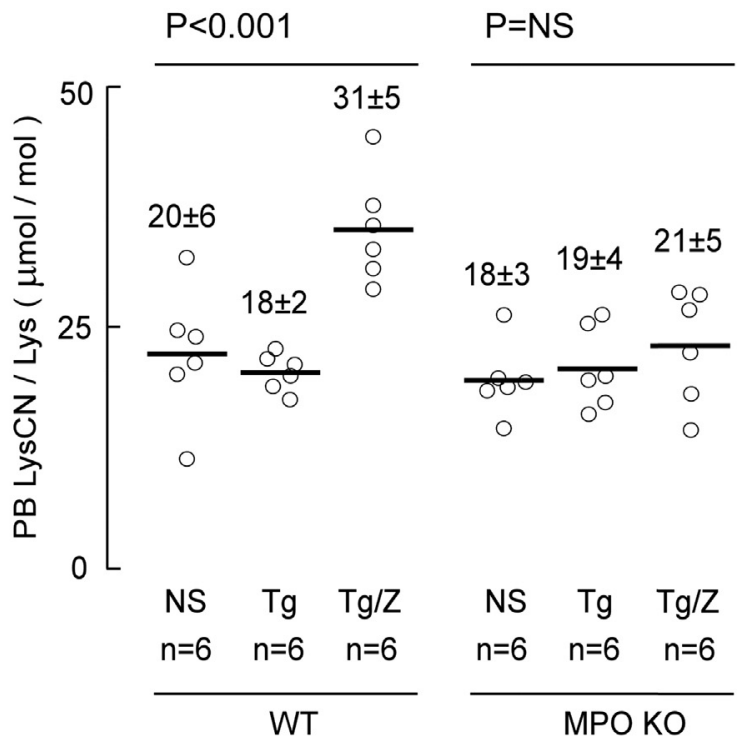

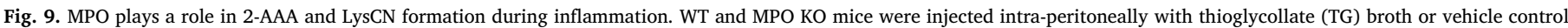

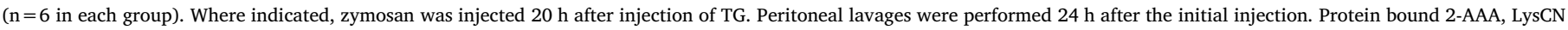

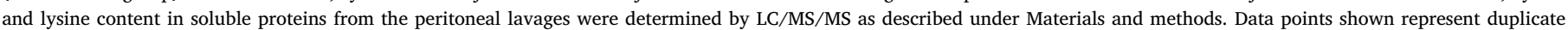

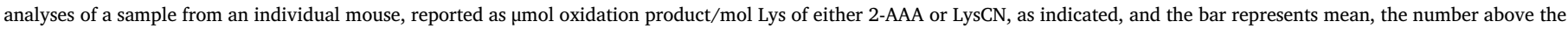
data points represents mean \pm S.D. P-value shown represents Kruskal-Wallis test within the indicated groups of mice. NS $=$ non-significant.

Free 2-AAA in peritoneal

lavage supernatant

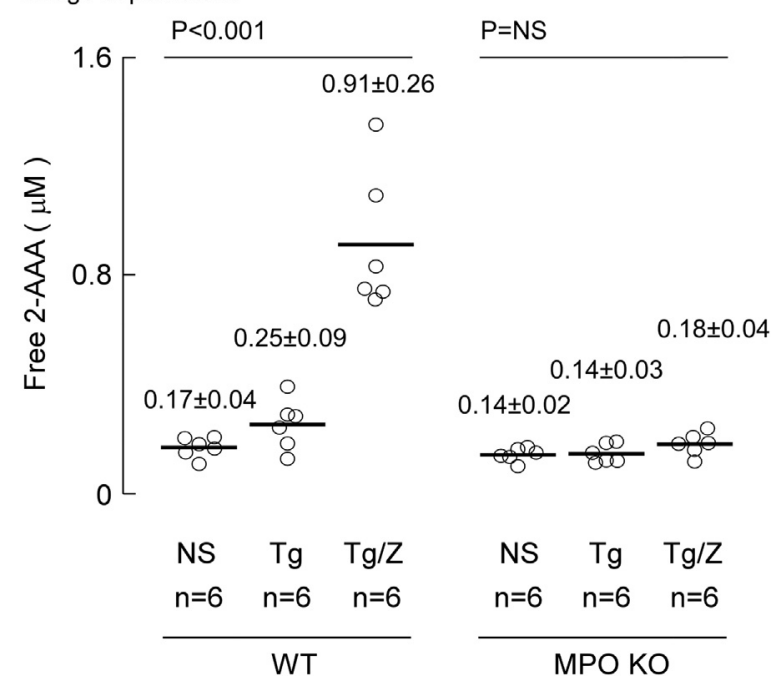

Fig. 10. Free 2-AAA level in zymosan induced peritonitis model. Free 2-AAA in WT and MPO-KO mouse peritoneal lavage under experimental conditions as described in Fig. 10 were quantified by stable isotope dilution LC/MS/MS (Materials and methods). Each data point represents the mean of duplicate analysis of sample from one mouse. Lines indicate mean levels within each group and values reported represent mean \pm S.D. P-value shown represents Kruskal-Wallis test within the indicated groups of mice. NS=non-significant.

Our studies reveal that prior analyses that reported detection of protein-bound 2-AAA in tissues likely overestimated 2-AAA formation due to acid catalyzed hydrolysis of protein-bound LysCN into 2-AAA. By using MPO-KO mice, our studies for the first time directly demonstrate that 2-AAA is a major product of protein lysyl residues oxidation by MPO at sites of inflammation. It should also be noted that in both WT and MPO-KO mice, protein bound 2-AAA and LysCN were both present at baseline and at approximately equal levels. Thus, these results strongly suggest that pathway(s) alternative to MPO also exist for
A PB-2-AAA in human aortic tissue B PB-LysCN in Human aortic tissue
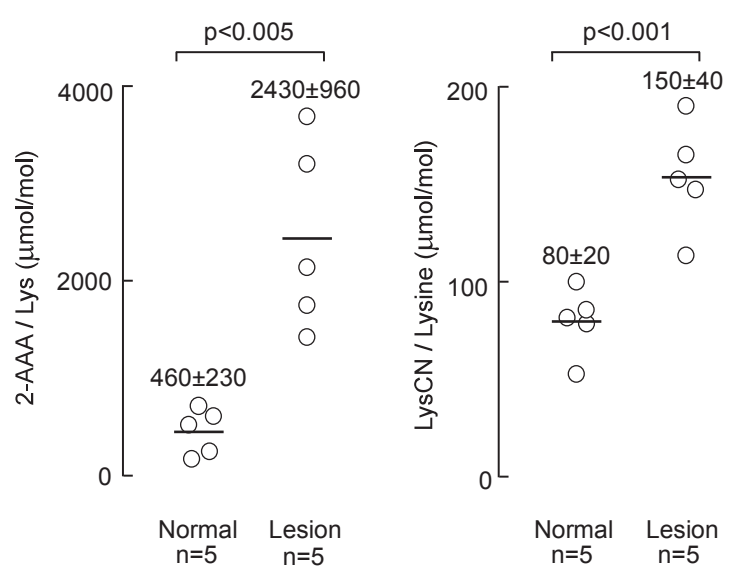

Fig. 11. Both 2-aminoadipic acid (2-AAA) and lysine nitrile (LysCN) are enriched in protein recovered from human aortic atherosclerotic tissues compared to normal aorta. Samples were prepared from normal human aortic tissue $(n=5)$ and atherosclerotic plaque-laden aortic tissue $(n=5)$. Protein bound 2-AAA and LysCN were quantified after protease-mediated hydrolysis by LC/MS/MS mass spectrometric analysis as described under methods. Data points shown represent duplicate analyses of a sample from an individual aorta, reported as $\mu \mathrm{mol}$ oxidation product/mol Lys of either 2-AAA or LysCN, as indicated, and the bar represents mean \pm S.D.

generation of these post translational modifications to protein lysyl residues. Different pathways have been reported to produce 2-aminoadipic- $\delta$-semialdehyde, including metal catalyzed oxidation [52,53], and lysyl oxidase [54]. Besides MPO mediated oxidation, it is also possible to form 2-AAA through further oxidation of 2 -aminoadipic- $\delta$-semialdehyde. We found MPO catalyzed oxidant of protein lysyl residues is one pathway producing 2-AAA in inflammatory diseases, however further studies of the origins of 2-AAA in different disease states are needed. Moreover, our studies also show an increase in free 2-AAA in mice following MPO catalyzed oxidation during inflammation. We presume 


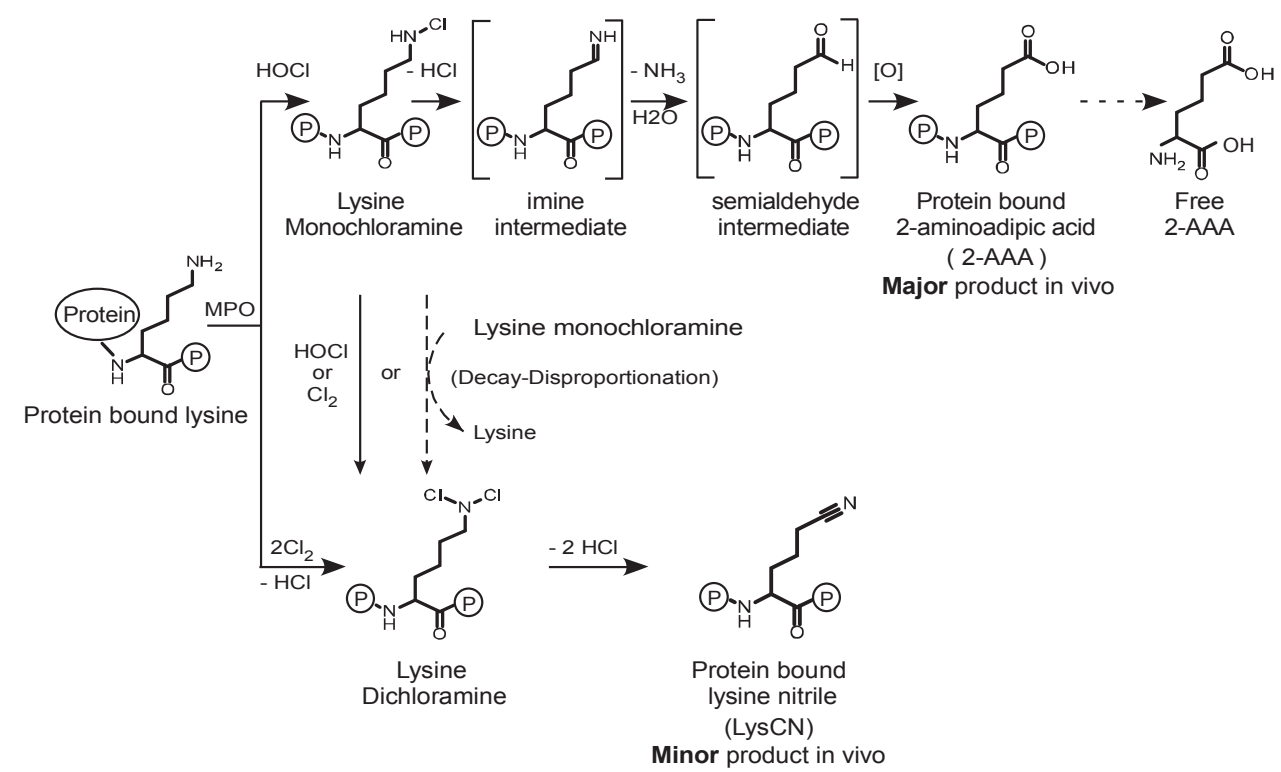

Fig. 12. Schematic illustration of reaction pathways for the formation of 2-AAA and LysCN by $\mathrm{MPO} / \mathrm{H}_{2} \mathrm{O}_{2} / \mathrm{Cl}^{-}(\mathrm{HOCl})$ oxidation of protein-bound lysine.

the free amino acid is a proteolytic degradation product of an MPOoxidized protein since levels of free 2-AAA were nominal at baseline, and markedly increased with inflammation in the WT but not MPO-KO mice. It also is noteworthy that in prior reported studies, exposure of free lysine to $\mathrm{HOCl}$ oxidizes lysine at the $\mathrm{N}^{\alpha}$-amine to form $\mathrm{N}^{\alpha}$ monochloramine, which then decomposes into a distinct aldehyde (and not 2-AAA) via a different pathway $[7,8]$. Thus, MPO-catalyzed generation of free 2-AAA observed in our animal model studies presumably arose from oxidation of protein-bound Lys, and not free Lys.

Our findings thus suggest MPO is a likely source of 2-AAA in vivo. While not directly examined in the present studies, we suspect MPOmediated oxidation is a major pathway responsible for the elevation of protein-bound 2-AAA and LysCN in human atherosclerotic plaque, since MPO and numerous characteristic oxidation products such as 3-chlorotyrosine are enriched in atherosclerotic plaque [27,55]. It is also notable that numerous studies have shown elevated levels of circulatory inflammatory factors in obese and prediabetic subjects [56], and a potential role of MPO in diabetes development has been suggested [57]. Inflammation of pancreatic islets is proposed to contribute to the development of type two diabetes [58], and elevated systemic MPO levels have been reported in patients with diabetes or insulin resistance [59]. Interestingly, prior studies with MPO-KO mice have shown protection from high fat diet-induced obesity and insulin resistance [57]. Based on these cumulative findings, more studies exploring the role of MPO, 2-AAA generation and development of insulin resistance seem warranted. Given the ongoing effort for generation of pharmacological agents that inhibit MPO as a potential therapeutic for the treatment of atherosclerosis, it will be interesting to see if such agents also have a potential salutary effect on prevention of prediabetes and diabetes development.

The present studies focused primarily on chemical mechanisms responsible for post translational modification of protein lysyl residues and their conversion into 2-AAA and LysCN. The biological consequences of 2-AAA and LysCN formation on target proteins by MPOmediated oxidation are unknown. Under physiological conditions, lysine's $\varepsilon$-amino side chain is positively charged, and often participates in hydrogen bonds and salt bridges, which are crucial to protein structure and function. The modification of lysine to 2-AAA alters its charge from positive to negative, which changes the interaction of this posttranslationally-modified lysine with surrounding molecules. It is thus likely that such oxidative modification to a protein could cause conformational changes at affected local sites, and it can be envisioned to potentially alter protein function. Considering the high content of lysine residues in proteins and the low abundance of MPO modifications, future studies should pay particular emphasis on possible gain of function modifications to protein lysine residues mediated by MPO. It is also noteworthy that the protein bound 2aminoadipate $-\delta$-semialdehyde intermediate formed has potential to crosslink with a second lysyl residue, which also would of course change protein structure and possibly function. Our studies revealing the end products of MPO-mediated oxidation of lysine in vivo and the reaction mechanisms involved can help to better understand potential functional changes of oxidized proteins found at the sites of inflammation in future investigations.

\section{Conflict of interest}

Drs. Hazen, Wang and Levison are named as co-inventors on pending patents held by the Cleveland Clinic relating to cardiovascular diagnostics. Dr. Hazen reports having been paid as a consultant for the following companies: Esperion and P \& G. Dr. Hazen reports receiving research funds from Astra Zeneca, P \& G, Pfizer Inc., Roche and Takeda. Drs. Hazen, Wang and Levison report having the right to receive royalty payments for inventions or discoveries related to cardiovascular diagnostics or therapeutics from Cleveland Heart Lab; and Dr Hazen from Siemens, Esperion, Frantz Biomarkers, LLC. All other authors have no relationships to disclose.

\section{Author contributions}

HL played a role in the design, performance and analyses of all studies and the initial drafting of the manuscript. BL helped with synthesis, HPLC purifications and high resolution mass spectrometry studies, as well as partial drafting of the manuscript. XF, ZW, VG, and JAD assisted with study design and data analyses. YH with JAB assisted with all in vivo studies. SLH conceived of project idea, assisted in design and analyses of experiments, and the drafting of the manuscript. All authors critically reviewed the manuscript. 


\section{Acknowledgements}

This study was supported by National Institutes of Health Grant P01 HL076491, R01 HL128300, R01 HL128268, and R01 DK106000. V.G. acknowledges support from Cleveland State University through the Faculty Scholarship Initiative and Faculty Research Development Awards.

\section{References}

[1] Y.F. Chang, Lysine metabolism in the human and the monkey: demonstration of pipecolic acid formation in the brain and other organs, Neurochem. Res. 7 (1982) 577-588.

[2] F. Papes, E.L. Kemper, G. Cord-Neto, F. Langone, P. Arruda, Lysine degradation through the saccharopine pathway in mammals: involvement of both bifunctional and monofunctional lysine-degrading enzymes in mouse, Biochem. J. 344 (Pt 2) (1999) 555-563.

[3] T.J. Wang, D. Ngo, N. Psychogios, A. Dejam, M.G. Larson, R.S. Vasan, A. Ghorbani, J. O'Sullivan, S. Cheng, E.P. Rhee, S. Sinha, E. McCabe, C.S. Fox, C.J. O'Donnell, J.E. Ho, J.C. Florez, M. Magnusson, K.A. Pierce, A.L. Souza, Y. Yu, C. Carter, P.E. Light, O. Melander, C.B. Clish, R.E. Gerszten, 2-Aminoadipic acid is a biomarker for diabetes risk, J. Clin. Investig. 123 (2013) 4309-4317.

[4] S.J. Klebanoff, Oxygen metabolism and the toxic properties of phagocytes, Ann. Intern. Med. 93 (1980) 480-489.

[5] A. Daugherty, J.L. Dunn, D.L. Rateri, J.W. Heinecke, Myeloperoxidase, a catalyst for lipoprotein oxidation, is expressed in human atherosclerotic lesions, J. Clin. Investig. 94 (1994) 437-444.

[6] L.K. Folkes, L.P. Candeias, P. Wardman, Kinetics and mechanisms of hypochlorous acid reactions, Arch. Biochem. Biophys. 323 (1995) 120-126.

[7] S.L. Hazen, A. d'Avignon, M.M. Anderson, F.F. Hsu, J.W. Heinecke, Human neutrophils employ the myeloperoxidase-hydrogen peroxide-chloride system to oxidize alpha-amino acids to a family of reactive aldehydes. Mechanistic studies identifying labile intermediates along the reaction pathway, J. Biol. Chem. 273 (1998) 4997-5005.

[8] S.L. Hazen, F.F. Hsu, A. d'Avignon, J.W. Heinecke, Human neutrophils employ myeloperoxidase to convert alpha-amino acids to a battery of reactive aldehydes: a pathway for aldehyde generation at sites of inflammation, Biochemistry 37 (1998) 6864-6873.

[9] S.L. Hazen, F.F. Hsu, D.M. Mueller, J.R. Crowley, J.W. Heinecke, Human neutrophils employ chlorine gas as an oxidant during phagocytosis, J. Clin. Investig. 98 (1996) 1283-1289.

[10] E.A. Podrez, D. Schmitt, H.F. Hoff, S.L. Hazen, Myeloperoxidase-generated reactive nitrogen species convert LDL into an atherogenic form in vitro, J. Clin. Investig. 103 (1999) 1547-1560.

[11] D.Q. Peng, Z. Wu, G. Brubaker, L. Zheng, M. Settle, E. Gross, M. Kinter, S.L. Hazen, J.D. Smith, Tyrosine modification is not required for myeloperoxidase-induced loss of apolipoprotein A-I functional activities, J. Biol. Chem. 280 (2005) 33775-33784.

[12] D.R. Sell, C.M. Strauch, W. Shen, V.M. Monnier, 2-aminoadipic acid is a marker of protein carbonyl oxidation in the aging human skin: effects of diabetes, renal failure and sepsis, Biochem. J. 404 (2007) 269-277.

[13] D.R. Sell, C.M. Strauch, W. Shen, V.M. Monnier, Aging, diabetes, and renal failure catalyze the oxidation of lysyl residues to 2-aminoadipic acid in human skin collagen: evidence for metal-catalyzed oxidation mediated by alpha-dicarbonyls, Ann. N. Y. Acad. Sci. 1126 (2008) 205-209.

[14] D.Q. Peng, G. Brubaker, Z. Wu, L. Zheng, B. Willard, M. Kinter, S.L. Hazen, J.D. Smith, Apolipoprotein, A-I tryptophan substitution leads to resistance to myeloperoxidase-mediated loss of function, Arterioscler. Thromb. Vasc. Biol. 28 (2008) 2063-2070.

[15] J.K. Bhattacharjee, alpha-aminoadipate pathway for the biosynthesis of lysine in lower eukaryotes, Crit. Rev. Microbiol. 12 (1985) 131-151.

[16] T.M. Zabriskie, M.D. Jackson, Lysine biosynthesis and metabolism in fungi, Nat. Prod. Rep. 17 (2000) 85-97.

[17] T. Kosuge, T. Hoshino, The alpha-aminoadipate pathway for lysine biosynthesis is widely distributed among Thermus strains, J. Biosci. Bioeng. 88 (1999) 672-675.

[18] J.D. Sivey, S.C. Howell, D.J. Bean, D.L. McCurry, W.A. Mitch, C.J. Wilson, Role of lysine during protein modification by $\mathrm{HOCl}$ and $\mathrm{HOBr}$ : halogen-transfer agent or sacrificial antioxidant?, Biochemistry 52 (2013) 1260-1271.

[19] V.K. Krieble, C.I. Noll, The hydrolysis of nitriles with acids, J. Am. Chem. Soc. 61 (1939) 560-563.

[20] J.M. Zgliczyński, T. Stelmaszyńska, J. Domański, W. Ostrowski, Chloramines as intermediates of oxidation reaction of amino acids by myeloperoxidase, Biochim. Biophys. Acta 235 (1971) 419-424.

[21] W.E. Pereira, Y. Hoyano, R.E. Summons, V.A. Bacon, A.M. Duffield, Chlorination studies. II. The reaction of aqueous hypochlorous acid with alpha-amino acids and dipeptides, Biochim. Biophys. Acta 313 (1973) 170-180.

[22] R.A. Clark, S. Szot, M.A. Williams, H.M. Kagan, Oxidation of lysine side-chains of elastin by the myeloperoxidase system and by stimulated human neutrophils, Biochem. Biophys. Res. Commun. 135 (1986) 451-457.

[23] Z.D. Nightingale, A.H. Lancha Jr, S.K. Handelman, G.G. Dolnikowski, S.C. Busse, E.A. Dratz, J.B. Blumberg, G.J. Handelman, Relative reactivity of lysine and other peptide-bound amino acids to oxidation by hypochlorite, Free Radic. Biol. Med. 29 (2000) 425-433.

[24] D.I. Pattison, M.J. Davies, Absolute rate constants for the reaction of hypochlorous acid with protein side chains and peptide bonds, Chem. Res. Toxicol. 14 (2001) 1453-1464.

[25] C.L. Hawkins, D.I. Pattison, M.J. Davies, Hypochlorite-induced oxidation of amino acids, peptides and proteins, Amino Acids 25 (2003) 259-274.

[26] S.L. Hazen, J.R. Crowley, D.M. Mueller, J.W. Heinecke, Mass spectrometric quantification of 3-chlorotyrosine in human tissues with attomole sensitivity: a sensitive and specific marker for myeloperoxidase-catalyzed chlorination at sites of inflammation, Free Radic. Biol. Med. 23 (1997) 909-916.

[27] S.L. Hazen, J.W. Heinecke, 3-Chlorotyrosine, a specific marker of myeloperoxidasecatalyzed oxidation, is markedly elevated in low density lipoprotein isolated from human atherosclerotic intima, J. Clin. Investig. 99 (1997) 2075-2081.

[28] Z. Wang, S.J. Nicholls, E.R. Rodriguez, O. Kummu, S. Hörkkö, J. Barnard, W.F. Reynolds, E.J. Topol, J.A. DiDonato, S.L. Hazen, Protein carbamylation links inflammation, smoking, uremia and atherogenesis, Nat. Med. 13 (2007) 1176-1184.

[29] L. Zheng, M. Settle, G. Brubaker, D. Schmitt, S.L. Hazen, J.D. Smith, M. Kinter, Localization of nitration and chlorination sites on apolipoprotein A-I catalyzed by myeloperoxidase in human atheroma and associated oxidative impairment in ABCA1-dependent cholesterol efflux from macrophages, J. Biol. Chem. 280 (2005) $38-47$.

[30] J.C. Morris, Acid ionization constant of $\mathrm{HOCl}$ from 5 to 35 degrees, J. Chem. Phys. 70 (1966) 3798-3805.

[31] D.P. Nelson, L.A. Kiesow, Enthalpy of decomposition of hydrogen peroxide by catalase at 25 degrees $\mathrm{C}$ (with molar extinction coefficients of $\mathrm{H} 2 \mathrm{O} 2$ solutions in the UV), Anal. Biochem. 49 (1972) 474-478.

[32] S.L. Hazen, F.F. Hsu, J.W. Heinecke, p-hydroxyphenylacetaldehyde is the major product of L-tyrosine oxidation by activated human phagocytes. A chloridedependent mechanism for the conversion of free amino acids into reactive aldehydes by myeloperoxidase, J. Biol. Chem. 271 (1996) 1861-1867.

[33] S. Yamazaki, A simple and convenient method for the synthesis of nitriles by oxidation of primary amines with $\mathrm{NaOCl}$ in ethanol, Synth. Commun. 27 (1997) 3559-3564.

[34] A.V. Reddy, B. Ravindranath, Acetylation under ultrasonic conditions - convenient preparation of N-acetylamino acids, Synth. Commun. 22 (1992) 257-264.

[35] M.L. Brennan, W. Wu, X. Fu, Z. Shen, W. Song, H. Frost, C. Vadseth, L. Narine, E. Lenkiewicz, M.T. Borchers, A.J. Lusis, J.J. Lee, N.A. Lee, H.M. Abu-Soud, H. Ischiropoulos, S.L. Hazen, A tale of two controversies: defining both the role of peroxidases in nitrotyrosine formation in vivo using eosinophil peroxidase and myeloperoxidase-deficient mice, and the nature of peroxidase-generated reactive nitrogen species, J. Biol. Chem. 277 (2002) 17415-17427.

[36] W.H. Kruskal, W.A. Wallis, Use of ranks in one-criterion variance analysis, J. Am. Stat. Assoc. 47 (1952) 583-621.

[37] M.S. Coker, W.P. Hu, S.T. Senthilmohan, A.J. Kettle, Pathways for the decay of organic dichloramines and liberation of antimicrobial chloramine gases, Chem. Res. Toxicol. 21 (2008) 2334-2343.

[38] C.L. Hawkins, M.J. Davies, Reaction of HOCl with amino acids and peptides: EPR evidence for rapid rearrangement and fragmentation reactions of nitrogen-centred radicals, J. Chem. Soc. Perkin Trans. 2 (1998) 1937-1945.

[39] C.L. Hawkins, M.J. Davies, Hypochlorite-induced damage to proteins: formation of nitrogen-centred radicals from lysine residues and their role in protein fragmentation, Biochem. J. 332 (1998) 617-625.

[40] S.T. Test, M.B. Lampert, P.J. Ossanna, J.G. Thoene, S.J. Weiss, Generation of nitrogen-chlorine oxidants by human phagocytes, J. Clin. Investig. 74 (1984) 1341-1349.

[41] E.L. Thomas, M.B. Grisham, M.M. Jefferson, Preparation and characterization of chloramines, Methods Enzymol. 132 (1986) 569-585.

[42] R.L. Valentine, C.T. Jafvert, General acid catalysis of monochloramine disproportionation, Environ. Sci. Technol. 22 (1988) 691-696.

[43] E.L. Thomas, M.B. Grisham, M.M. Jefferson, Myeloperoxidase-dependent effect of amines on functions of isolated neutrophils, J. Clin. Investig. 72 (1983) 441-454.

[44] V.T. Vasu, S.J. de Cruz, J.S. Houghton, K.A. Hayakawa, B.M. Morrissey, C.E. Cross, J.P. Eiserich, Evaluation of thiol-based antioxidant therapeutics in cystic fibrosis sputum: focus on myeloperoxidase, Free Rad. Res. 45 (2011) 165-176.

[45] A.V. Peskin, C.C. Winterbourn, Kinetics of the reactions of hypochlorous acid and amino acid chloramines with thiols, methionine, and ascorbate, Free Radic. Biol. Med. 30 (2001) 572-579.

[46] C. Storkey, M.J. Davies, D.I. Pattison, Reevaluation of the rate constants for the reaction of hypochlorous acid $(\mathrm{HOCl})$ with cysteine, methionine, and peptide derivatives using a new competition kinetic approach, Free Radic. Biol. Med. 73 (2014) 60-66.

[47] S.J. Nicholls, S.L. Hazen, Myeloperoxidase and cardiovascular disease, Arterioscler. Thromb. Vasc. Biol. 25 (2005) 1102-1111.

[48] J. Williams, The decomposition of hydrogen peroxide by liver catalase, J. Gen. Physiol. 11 (1928) 309-337.

[49] C.C. Winterbourn, Comparative reactivities of various biological compounds with myeloperoxidase-hydrogen peroxide-chloride, and similarity of the oxidant to hypochlorite, Biochim. Biophys. Acta 840 (1985) 204-210.

[50] L.J. Hazell, J.J. van den Berg, R. Stocker, Oxidation of low-density lipoprotein by hypochlorite causes aggregation that is mediated by modification of lysine residues rather than lipid oxidation, Biochem. J. 302 (1994) 297-304.

[51] G.J. Handelman, Z.D. Nightingale, G.G. Dolnikowski, J.B. Blumberg, Formation of carbonyls during attack on insulin by submolar amounts of hypochlorite, Anal. Biochem. 258 (1998) 339-348.

[52] J.R. Requena, C.C. Chao, R.L. Levine, E.R. Stadtman, Glutamic and aminoadipic semialdehydes are the main carbonyl products of metal-catalyzed oxidation of proteins, Proc. Natl. Acad. Sci. USA 98 (2001) 69-74. 
[53] M. Akagawa, T. Sasaki, K. Suyama, Oxidative deamination of lysine residue in plasma protein of diabetic rats. Novel mechanism via the Maillard reaction, Eur. J. Biochem. 269 (2002) 5451-5458.

[54] L.I. Smith-Mungo, H.M. Kagan, Lysyl oxidase: properties, regulation and multiple functions in biology, Matrix Biol. 16 (1998) 387-398.

[55] J.W. Heinecke, F.F. Hsu, J.R. Crowley, S.L. Hazen, C. Leeuwenburgh, D.M. Mueller, J.E. Rasmussen, J. Turk, Detecting oxidative modification of biomolecules with isotope dilution mass spectrometry: sensitive and quantitative assays for oxidized amino acids in proteins and tissues, Methods Enzymol. 300 (1999) 124-144.

[56] J.C. Pickup, Inflammation and activated innate immunity in the pathogenesis of type 2 diabetes, Diabetes Care 27 (2004) 813-823.

[57] Q. Wang, Z. Xie, W. Zhang, J. Zhou, Y. Wu, M. Zhang, H. Zhu, M.H. Zou, Myeloperoxidase deletion prevents high-fat diet-induced obesity and insulin resistance, Diabetes 63 (2014) 4172-4185.

[58] M.Y. Donath, S.E. Shoelson, Type 2 diabetes as an inflammatory disease, Nat. Rev Immunol. 11 (2011) 98-107.

[59] S. Rovira-Llopis, M. Rocha, R. Falcon, C. de Pablo, A. Alvarez, A. Jover, A. Hernandez-Mijares, V.M. Victor, Is myeloperoxidase a key component in the ROS-induced vascular damage related to nephropathy in type 2 diabetes?, Antioxid. Redox Signal. 19 (2013) 1452-1458.

Post-print standardized by MSL Academic Endeavors, the imprint of the Michael Schwartz Library at Cleveland State University, 2019 